\title{
Sexual Dimorphisms in Innate Immunity and Responses to Infection in Drosophila melanogaster
}

\author{
Rebecca L. Belmonte ${ }^{1 \dagger}$, Mary-Kate Corbally ${ }^{1 \dagger}$, David F. Duneau ${ }^{2 * \ddagger}$ and \\ Jennifer C. Regan ${ }^{1 * \neq}$ \\ ${ }^{1}$ Institute of Immunology \& Infection Research, University of Edinburgh, Edinburgh, United Kingdom, ${ }^{2}$ Laboratoire Evolution \& \\ Diversite Biologique, UMR5174 EDB, CNRS, Université Toulouse 3 Paul Sabatier, Toulouse, France
}

\section{OPEN ACCESS}

Edited by:

Susanna Valanne,

Tampere University, Finland

Reviewed by:

Mark Austin Hanson,

École Polytechnique Fédérale de

Lausanne, Switzerland

llias Kounatidis,

Diamond Light Source,

United Kingdom

*Correspondence:

David F. Duneau

david.duneau@gmail.com

Jennifer C. Regan

jenny.regan@ed.ac.uk

tThese authors have contributed equally to this work and share first

authorship

¥These authors have contributed equally to this work and share last authorship

Specialty section:

This article was submitted to Comparative Immunology a section of the journal

Frontiers in Immunology

Received: 31 October 2019 Accepted: 16 December 2019 Published: 31 January 2020

Citation:

Belmonte RL, Corbally M-K,

Duneau DF and Regan JC (2020)

Sexual Dimorphisms in Innate

Immunity and Responses to Infection

in Drosophila melanogaster.

Front. Immunol. 10:3075.

doi: 10.3389/fimmu.2019.03075
The sexes show profound differences in responses to infection and the development of autoimmunity. Dimorphisms in immune responses are ubiquitous across taxa, from arthropods to vertebrates. Drosophila melanogaster shows strong sex dimorphisms in immune system responses at baseline, upon pathogenic challenge, and over aging. We have performed an exhaustive survey of peer-reviewed literature on Drosophila immunity, and present a database of publications indicating the sex(es) analyzed in each study. While we found a growing interest in the community in adult immunity and in reporting both sexes, the main body of work in this field uses only one sex, or does not stratify by sex. We synthesize evidence for sexually dimorphic responses to bacterial, viral, and fungal infections. Dimorphisms may be mediated by distinct immune compartments, and we review work on sex differences in behavioral, epithelial, cellular, and systemic (fat body-mediated) immunity. Emerging work on sexually dimorphic aging of immune tissues, immune senescence, and inflammation are examined. We consider evolutionary drivers for sex differences in immune investment, highlight the features of Drosophila biology that make it particularly amenable to studies of immune dimorphisms, and discuss areas for future exploration.

Keywords: Drosophila, Drosophila melanogaster, innate immunity, sex dimorphism, aging, response to infection, sexual antagonism

\section{INTRODUCTION}

Sex governs physiology: differences between males and females are strong drivers of variance in phenotype within any population, and can eclipse effects of geography or genotype $(1,2)$. The immune system is no exception. Sex differences in human immunity are profound, where men and women respond differently to infection, treatment, diseases such as sepsis, and have different propensities toward autoimmunity $(3,4)$. However, the mechanisms underpinning these dimorphisms are largely unresolved. A major reason for this lack of resolution is that sex differences in immunity are understudied; in particular, there is a paucity of truly comparative studies. A recent meta-analysis addressing the issue of sex as a variable in biomedical studies showed that immunology as a discipline is particularly negligent, with fewer than $10 \%$ of studies reporting, or stratifying, by sex (5). Historically, women have been excluded from clinical trials and young males presented as "the norm," in part due to concerns for potential impacts on fetal health (6). Parity has not been reached in representation (7) or reporting (8) of the sexes, despite the effective ban on women participating in clinical trials ending in the 1980s (6). In addition, in studies 
using laboratory model organisms, practical and budgetary considerations have led to the common practice of using a single sex. Recently, there has been recognition of the loss of knowledge propagated by the lack of inclusion of both sexes, with a drive from the scientific community to address the "gender gap," including $\mathrm{NIH}$ and ERC commitments to address this specifically $(9,10)$.

The effects of immune dimorphisms are not only a consideration for clinical research, but also impact our broader understanding of host-pathogen interactions. Sex differences in immunity are observed throughout taxa, and are both cause and consequence of sex differences in life history, and sexual conflict. Responses to infection influence survival and fecundity, and therefore immune dimorphisms have the potential to affect both horizontal and vertical disease transmission throughout the animal kingdom (11). Inherant in the consideration of sex and immunity is complexity: within a single species, dimorphisms themselves are pathogen-specific (12), can respond to environmental variables such as diet $(13,14)$, and may even be influenced by the infective parasite which can be differently adapted to each sex (15). Adding further complexity is the interaction of immunity and sex with organism age (16).

As is the case for all insects, Drosophila melanogaster physiology is sexually dimorphic (17-19), yet despite its use for more than a century as a model organism, the extent of these dimorphisms are only just being fully appreciated (20). Sex differences are seen in immune tissues $(21,22)$ and in responses to infection (23), yet relatively few studies include both sexes. Studies that explicitly compare immune responses in both sexes in Drosophila reflect what is seen in other taxa in terms of prevalence and complexity: dimorphic responses are the norm rather than the exception, the direction that dimorphisms take with respect to the opposite sex is both pathogen- and contextdependent (23), and sex differences at baseline are not necessarily predictive of survival outcome (24).

\section{What Can Drosophila Teach Us About Immune Dimorphism?}

Drosophila species have been used for many decades to study sexual antagonism in the evolutionary ecology field (25-27). We argue that including, and comparing, both sexes in functional and mechanistic studies of Drosophila immunity will add to this body of work to give important insight to several fields, in addition to better understanding host-pathogen interactions from an evolutionary ecology perspective. It will, for example, offer translatable information on disease vector biology, where sex is a crucial variable for exposure, transmission, and control strategies of insect disease vectors such as mosquitos (28-30). Drosophila provides a tractable model for innate immunity in mammals, as has been amply demonstrated over recent decades (31): studies on Drosophila could help understand rules underpinning sexual dimorphism in mammalian immunity and response to infections. Sex differences in mammalian immunity are often attributed solely to the action of steroid hormones. Interactions between steroid hormones and the immune system have also been demonstrated in Drosophila
$(32,33)$, which may parallel endocrine-immune interactions in mammals. Mammalian immune dimorphisms arise not only as a consequence of selective pressures on the endocrine system. A large body of studies in mammalian immunology has uncovered many dimorphisms, particularly in autoimmune disease etiology, that are regulated by karyotype, independent of hormonal action (34-36). While it is difficult to attribute autoimmunity to organisms without immune self-recognition, direct self-damage by immune responses on the host has been demonstrated in Drosophila $(37,38)$ and may differ depending on the sex (39). Drosophila, like mammals, bear X and Y sex chromosomes, and both $\mathrm{X}$ - and Y-linked variation in immune responses have been demonstrated $(40,41)$. This, in combination with the strong conservation of immune signaling pathways (as exemplified by Toll/TLRs), makes Drosophila a powerful model for sex-specific genetic regulation of molecular immunity $(23,42)$.

\section{A Survey of Immunity Studies Using Adult Drosophila melanogaster}

We have undertaken to perform a survey of peer-reviewed, published studies of $D$. melanogaster immunity, reporting on the representation of sex within each study. We have focussed on studies using adult flies, while also identifying papers that use juveniles, cell cultures, or pre-existing genetic data. We searched for Drosophila immunity papers through Web of Science, attempting to avoid studies of other model organisms that mentioned Drosophila. As of the 21 August 2019, we downloaded the citations for the resulting 5,626 publications and manually categorized each paper. Two thousand eight hundred and forty-eight papers were removed since Drosophila were not used in the study, or the focus of the study was not immunity. We also made a decision to exclude the 166 endosymbiont studies that used both sexes from our analysis. There were also three papers which we could not access, which were removed (4345). Of the remaining 2,614 papers, 1,369 used adults, 817 used juveniles, 396 were non-experimental (i.e., reviews or methods), and 30 were bioinformatics studies (Figure 1A). In the last 30 years, we can see how the Drosophila immunity field has grown and the relative use of adults or juveniles has changed. In 1990, only two adult studies and three juvenile studies were published (Figure 1B). Initially, the majority of studies were conducted on juveniles, but by 2010, the trend had reversed, where 75 studies used adults and 47 used juveniles. The use of adult Drosophila to study immunity has continued to grow, averaging over 100 adult studies per year between 2012 and 2018 (Figure 1B). Of the adult studies, $41 \%(564 / 1,369)$ did not report the sex, or did not stratify data by sex. When sex was reported, $45 \%$ used only one sex, with more studies using females $(28 \% ; 378 / 1,366)$, than males $(18 \%$; $243 / 1,366)$. Only $13 \%(184 / 1,366)$ of all adult studies reported results for both males and females ("both" category; Figure 1C). We additionally tagged each paper in the "both" category with the study type or data output (Figure 1D, Figure S1). Tags were not exclusive, where studies could be assigned multiple tags, resulting in more tags than articles in the output. The two most common tags were "gene function/knockout" (23\%; 76/334), 

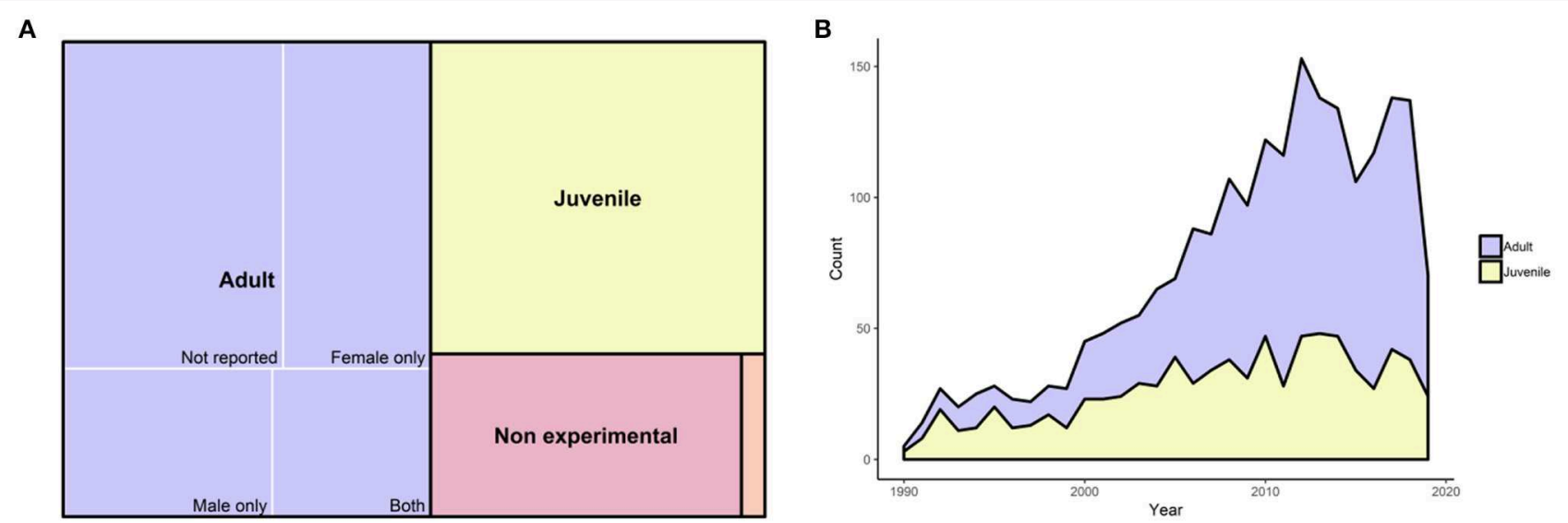

c

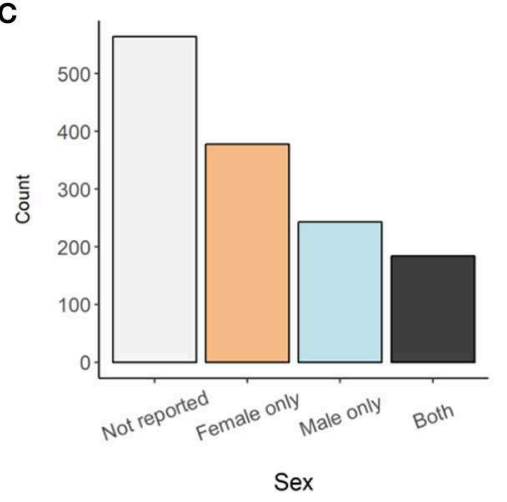

D

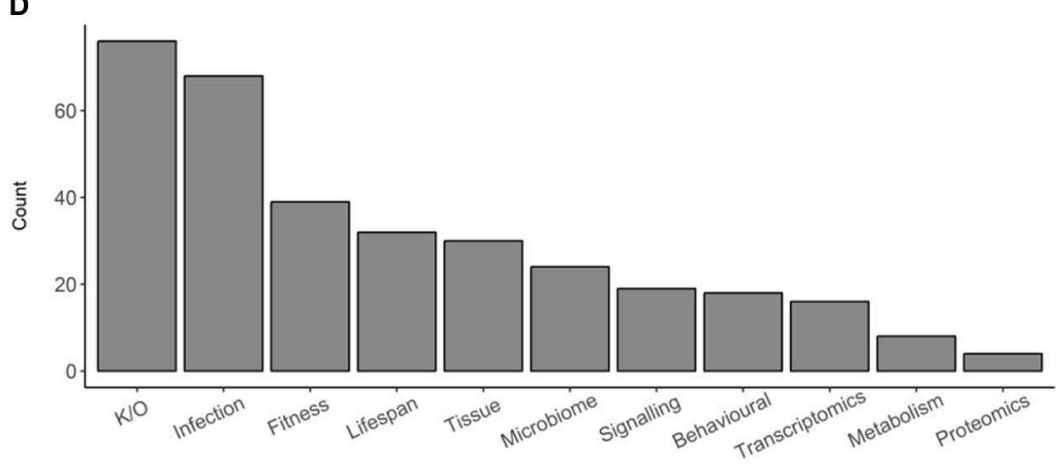

FIGURE 1 | Composition of 2,614 articles on Drosophila immunity. (A) Categories used for all Drosophila immunity studies. Size of each rectangle is proportional to the number of articles within that category. The largest proportion are adult studies (purple; 1,366), followed by juvenile (yellow; 817), non-experimental (pink; 396), and bioinformatic (orange; 30) studies. (B) The quantity of articles published since 1990 until 21 August 2019 that use either adult (purple) or juvenile (yellow) Drosophila. (C) Quantity of adult Drosophila studies that do not report sex used (purple; 561), use females (pink; 378), use males (orange; 243), or use both sexes (yellow; 184). (D) Total number of articles that used both sexes, tagged according to experimental output. Tags are not exclusive, so some articles may have more than one tag. The tags used were gene function knock out (46), survival infection dynamics (47), fitness (39), lifespan (32), tissue specific (30), microbiome (24), signaling (19), behavioral (18), transcriptomics (16), metabolism composition (8), and proteomics (4).

followed by "survival/infection dynamics" (20\%; 68/334). The survey information is available as a searchable table, intended as a resource for locating data on immunity in both sexes (Table S1). Integrating information from this wealth of published data, we review what is reported about sex dimorphisms in immunity in Drosophila.

\section{SEX DIFFERENCES IN INFECTION OUTCOMES}

\section{Survival and Pathology}

Drosophila exhibit dimorphic survival and pathology in response to bacterial, viral, and fungal infections. Importantly, dimorphic survival and prevalence of infection are pathogen- and contextspecific (Table 1).

\section{Viral Infection}

Few studies have compared male and female responses to viral infection in D. melanogaster. Males are possibly more susceptible to acute viral infection: they demonstrate lower survival to the recently-described, DNA virus Kalithea $(\mathrm{KV})$, which was isolated from infected individuals caught from a wild population (48). Males are also more susceptible to higher viral titers of the RNA virus Drosophila C (DCV) (59). Notably, dimorphism in survival to viral infection might be influenced by coinfection with Wolbachia, an endosymbiont providing viral protection (60). Indeed, interactions between DCV and Wolbachia infection status and sex have been observed in analyses of behavioral responses (61), discussed in more detail below.

Other effects of viral infection can impact the sexes differently, in addition to survival. For example, although females infected with KV generally survive, they suffer from ovary degeneration and a strong reduction in fecundity (48). Viral-induced female infertility is known to occur in infections with flock house virus (FHV) due to oocyte destruction (62). Thus, conclusions on sexspecific impacts of viral infection on fitness need to consider all consequences of infection, not just survival.

\section{Viral Transmission}

A recent study demonstrated that male-biased DCV titers are accompanied by higher levels of fecal shedding (59), which is in apparent contrast to an earlier study that found females to 
TABLE 1 | Reported sex biases in survival to infection by specific pathogens.

\begin{tabular}{lllc}
\hline Class & Pathogen & $\begin{array}{l}\text { Survival } \\
\text { bias-direction }\end{array}$ & References \\
\hline Viral & Kalithea & Female & $(48)$ \\
Fungal & Beauveria bassiana & Male & $(49-53)$ \\
& Metarhizium anisopliae & Male & $(54)$ \\
& Candida albicans & Female & $(55)$ \\
Microsporidial & Tubulinosema ratisbonensis & Female & $(56)$ \\
Bacterial & Pseudomonas aeruginosa & Male & $(46)$ \\
gram-negative & Pseudomonas aeruginosa & Female & $(55)$ \\
& Pseudomonas fluorescens & Female & $(22)$ \\
& Providencia rettgeri & Male & $(23)$ \\
& Providencia alcalifaciens & Male & $(23)$ \\
& Coxiella burnetii & - & $(57)$ \\
& Serratia marcescens & Female & $(58)$ \\
Gram-positive & Enterococcus faecalis & Male & $(23)$ \\
& Lactococcus lactis & Female & $(58)$ \\
\hline
\end{tabular}

be better transmitters of DCV than males (63). It is not known whether load, or rates of shedding, are necessarily predictive of the ability of each sex to transmit viral infection; this may be dependent upon several additional factors, including infection route and behavioral responses to infection. Further studies correlating viral load and shedding with the ability to transmit infection in both sexes will be informative. Verticallytransmitted viruses by definition interact with host sex, given their route through infected gonads. For example, Sigma virus (Rhabdoviridae), a negative-stranded RNA virus, is transmitted vertically through the sperm or ovules. Male transmission of Sigma virus is required for persistence in the population, while transmission efficiency is higher for females than males (64). Infection with Sigma virus leads to sexually dimorphic gene induction, with more gene expression changes induced by infection in males than females (65). Infected females significantly upregulate structural chorion proteins, which could reflect manipulation by the virus to aid vertical transmission, or an ovary-specific defense response.

Given the very small number of studies addressing dimorphisms in survival to viral infections, we do not yet have the ability to make inferences about sex differences in antiviral responses, nor indeed whether there are differences between responses to RNA and DNA viruses, or diverse viral species.

\section{Fungal and Microsporidial Infection}

To our knowledge, there are only a small number of studies investigating sexual dimorphism in fungal infection. Indeed there is a dearth of studies investigating sex-specific physiological responses to such challenges (Figure 2). The most commonly studied fungal infection model, Beauveria bassiana, exhibits male-biased survival when flies are challenged via spore inoculation (49-53). The dimorphism appears to be, at least partly, attributable to dimorphic function of the Toll pathway, where loss-of-function mutants in Toll pathway components lose the sex difference in survival $(52,53)$. A similar male bias in survival is observed post-inoculation with the soil fungus Metarhizium anisopliae (54). However, although not directly compared, males appear to be more susceptible to systemic Candida albicans challenge by means of intra-thoracic injection (55). Interestingly, the effect of Toll-1 and Toll-7 mutation on resistance to $C$. albicans challenge revealed a greater sensitivity of male mutants to this fungal infection, while Toll-7 mutant females demonstrated resistance similar to that of controls (55). In addition, males succumbed to systemic infection with the microsporidium Tubulinosema ratisbonensis sooner than did females (56), despite a lower reported microsporidial load. However, the assertion made here that despite a greater lethality to $T$. ratisbonensis, males show a higher resistance as demonstrated by their lower pathogen load, needs further investigation. Pathogen load should be quantified before significant mortality has occurred in the population of infected individuals, otherwise, individuals with a high pathogen load who died prior to sampling would not be included in the analysis. A greater number of infected males had died 5 days post-infection from $T$. ratisbonensis than females, and pathogen load was analyzed 6 days post-infection (56). These results could potentially suggest that males are less tolerant, given that the only individuals still alive are those carrying a lower pathogen load.

Overall, in contrast to viral infections, males appear to survive longer than females in fungal infection models. There are indications that the magnitude of these dimorphisms in survival may be dependent on the environment. For example, the male-biased survival observed upon infection with $B$. bassiana is magnified by cold pretreatment of flies before infection, improving male survival at young and middle ages (81). Diet is also likely to influence susceptibility; for example, while females have decreased rates of survival to $B$. bassiana thoracic injection, immunity-induced metabolic declines were $50 \%$ greater in males (82). Supporting the interaction of metabolic state with sex-biased infection outcomes, polymorphisms associated with increased resistance to M. anisopliae inoculation are dimorphic and are biased toward gene networks regulating metabolism, as well as phagocytosis and cell migration (83). Furthermore, in the microsporidia infection model $T$. ratisbonensis, the quantity of circulating triglycerides was shown to affect parasite burden in females (56). The intersection of diet, metabolism and immune responses is likely to dictate outcomes to infection with most (or all) pathogens, as we discuss in more detail below. However, whether metabolic effects regulate resistance or tolerance to the fungal and microsporidial infection models described is as yet untested.

\section{Bacterial Infection}

The bacterial genus of Wolbachia and Spiroplasma have welldocumented interactions with host sex and have been extensively studied in Drosophila infection models. Both bacteria disrupt the reproductive biology of their hosts, and show sex-specific transmission. While these interactions are entirely dependent on host sex, these examples are not strictly relevant to examination of dimorphic immune responses, and have already 

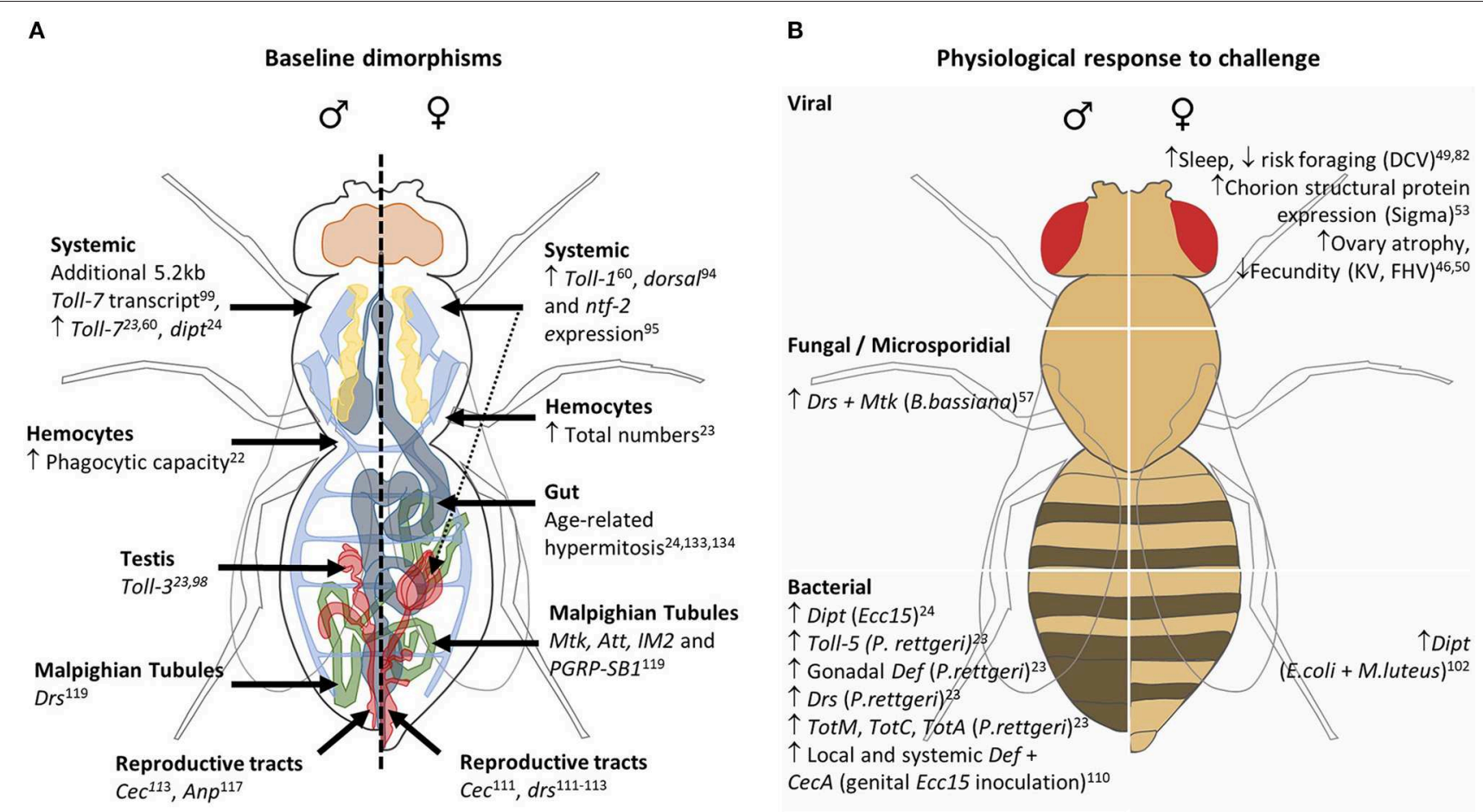

FIGURE 2 | Schematic representing sexual dimorphisms in innate immunity at basal state (A) and in physiological responses to immune challenge (B). (A) Male- and female-specific baseline conditions are depicted on the left and right of the central dashed line, respectively. Greater expression/ numbers are denoted by an upward-facing arrow, while stand-alone genes belonging to systemic or specific tissues represent sex-specific expression systemically or within that tissue, respectively. The dashed arrow represents the potential contribution made by the ovaries to observed differences in systemic transcript abundance. (B) Male (left column) and female (right column) physiological responses to viral, fungal/microsporidial, and bacterial are listed, with the causative pathogen in brackets. Increases and decreases in expression or behaviors are denoted by upward- and downward-facing arrows, respectively.

been extensively reviewed $(47,84-87)$, so we will not focus on them here.

In models of systemic bacterial infection of male and female adults, where immune responses and survival are directly compared, survival to infection appears to be pathogendependent. Depending on the amount and type of peptidoglycan (sugar- and amino acid-based polymers) in their cell wall, bacteria can be categorized into two groups, Gram-positive (G-) and Gram-negative (G-). In Drosophila, the production of immune effectors such as antimicrobial peptides is under the control of the immune deficiency (IMD) and the Toll signaling pathways. The former responds to the meso-diaminopimelic acid (DAP)-type peptidoglycan of G- bacteria and certain G+ bacilli, whereas the Toll signaling pathway responds mainly to the lysine (Lys)-type peptidoglycan of G+ bacteria and fungal beta-1-3glucan $(88,89)$. Activation of immune signaling pathways are not strictly dictated by cell wall type, however; for example, both Toll and IMD signaling pathways are activated by Staphylococcus aureus infection (90).

It is not possible to neatly attribute the direction of sexbiased survival to bacterial infection to one particular signaling pathway. Males appeared to be more resistant to systemic infections by the extracellular G- Providencia species Providencia rettgeri and Providencia alcalifaciens $(23,91)$. However, mortality to the obligate intracellular Coxiella burnetii is comparable in males and females (57), while males died more quickly than females when infected with Pseudomonas fluorescens (22), or the extracellular bacteria Serratia marcescens (although notably, this was genotype-specific) (58). Few studies have assessed the response of both sexes to $\mathrm{G}+$ bacteria. Females were reported to be more susceptible to infection with Enterococcus faecalis but less to S. aureus (23) or to Lactococcus lactis (58). Thus far, laboratory models of bacterial infection have demonstrated both male- and female-biased survival with Gand $\mathrm{G}+$ species (Table 1). Different laboratories have also reported opposite biases in response to the same pathogen. For example, Pseudomonas aeruginosa is reported to induce dimorphic survival that is either male- or female-biased (46, 55), or not significantly different (22). These contrasting results may be dictated by genotype, as is evidently the case for malebiased susceptibility to $S$. marcescens, which was observed in only two out of four genetic backgrounds tested in a recent study (58). These results may also be influenced by environmental conditions such as mating status, which appears to have an immunosuppressive effect on females (23, 92, 93). Another probable reason a clear pattern has not emerged is that the bacterial species used in these infection models are more diverse than the peptidoglycan dichotomy belies. Compared to P. rettgeri, 
S. marcescens is highly pathogenic to Drosophila, and its infection dynamic within the host is very different (23). Moreover, while these two bacteria are extracellular, other species, such as Coxiella, infect intracellularly, further complicating the comparison. Different pathogens require different host defense mechanisms, which may rely on particular immune tissues, signaling pathways, and terminal effectors such as AMPs. A more systematic comparison between male and female responses to a range of different bacteria with different modes of infection will help to decipher the role for immune signaling pathways in dimorphism.

A role for the Toll pathway in mediating sex differences in survival to some bacterial infections has recently started to emerge. It appears to be necessary for dimorphic survival to $P$. rettgeri, and loss of Toll signaling reverses the survival bias to E. faecalis (23). Loss-of-function mutants of both Toll-1 and Toll-7 differentially affected infection outcomes in males and females. Toll-1 mutant males and females were less resistant to $E$. faecalis challenge than wild-type controls, while loss-of-function Toll-7 mutants reduced male resistance to both E. faecalis and P. aeruginosa (55).

\section{Behavioral Responses and Symptoms}

In addition to dimorphic immune responses, Drosophila exhibit sex-specific behavioral symptoms and responses to infection. Grooming is thought to be an important behavioral defense against pathogenic infection, where flies remove potentially infectious microbes from their cuticle. Grooming in $D$. melanogaster is triggered by chemosensation of compounds, including pathogen components, by chemoreceptive sensilla. Specifically, the sensing receptor PRGP-LC contributes to grooming induction, connecting humoral immune sensing to behavioral responses (94). In optogenetic experiments targeting sensilla, grooming was more readily triggered in males than in females (94). Females were subsequently shown to rely more strongly on olfactory signals to remove cuticular $B$. bassiana than males, resulting in more conidia on the wings of olfactorydeficient female flies (95), but whether this contributes to the higher rate of survival by males after B. bassiana infection (49-53) remains to be seen. Drosophila exhibit dimorphic sleep responses to infection, a behavioral change which may be adaptive, or symptomatic. DCV causes females, but not males, to sleep more; however, DCV-infected male flies carrying Wolbachia are more lethargic when awake (61). Many other behaviors are likely to be impacted by symptoms such as lethargy and sleep alterations, including evasive behaviors and mating. For example, Wolbachia infection increases the recapture rate of females, but not males (96). Females previously exposed to DCV showed lower motivation to pick a food source when presented with a risk of encountering DCV (78). When disrupted, nemuri, an antimicrobial peptide that promotes sleep in $D$. melanogaster, reduced day-time sleep consolidation selectively in males (97), potentially linking dimorphic sleep behavior and responses to immune challenge. During a $P$. rettgeri systemic infection, females arrested egg-laying during the acute phase of the infection, until it stabilized into a chronic phase (98). The same observation has been made upon benign infections with Pectobacterium carotovorum (previously named Erwinia carotovora carotovora, or Ecc15) and Escherichia coli (99). The adaptive role of this behavioral response $(99,100)$ is not clear and is by definition female-specific. It remains to be determined if changes to reproductive behavior occur in males. Although research in this area is in its infancy, these studies suggest behavioral dimorphisms in D. melanogaster could be an important driver for sex differences in infection outcome.

\section{SEX DIFFERENCES IN IMMUNE COMPARTMENT PHYSIOLOGY}

Sex differences in outcome to infection are likely to be mediated by distinct immune compartments, where the key tissues involved will be dependent on pathogen and route of infection. Below we discuss those studies that assess the contribution of individual immune tissues. Sexually dimorphic immune physiologies in unchallenged flies and after acute infection are summarized in Figure 2.

\section{Hemocytes}

Hemocytes are specialized immune cells responsible for the encapsulation and phagocytosis of pathogens and dead cells. Few studies focusing on D. melanogaster hemocytes have reported the sex of individuals used; but those that have, present some evidence suggestive of a dimorphism in this branch of the immune system. First, it appears that hemocytes can have sexspecific functions. The Jun N-terminal kinase (JNK) signaling pathway regulates the decision between cell repair and cell death. As such, JNK/Basket is required in larval hemocytes to promote tissue maintenance, but only in males, such that hemocytespecific loss of JNK/Basket results in increased tissue damage in males after UV irradiation (101). In addition to this functional difference, there is some evidence for sex differences in total hemocyte number, but neither the direction of bias nor the drivers for the dimorphism can yet be concluded. Female white prepupae have been reported to contain a higher total number of hemocytes than males (102). In adults, higher numbers of hemocytes per se in females (23), and higher numbers of hemocytes per unit of hemolymph in males (21), have been reported, whilst a recent study found no effect of sex on adult hemocyte number (22). A subtly higher phagocytic index has been reported for male hemocytes ex vivo (22); however, sex differences in the functional roles of hemocytes in homeostasis or responses to infection are as yet unknown.

\section{Melanisation}

Melanogenesis is an important feature of arthropod physiology. In addition to its role in cuticular hardening, via the synthesis of a specific melanin called sclerotin, and in cuticular coloration, via the synthesis of eumelanin, multiple studies have demonstrated its role in immune responses [see (103) for review]. An essential role for immune melanization in the efficient killing of encapsulated parasitoid wasp eggs and pathogens via cytotoxicity of reactive oxygen species (ROS) produced by the melanization cascade is well-appreciated $(104,105)$. The process hinges on cascades of serine proteases (SPs) triggered by either direct or 
indirect antigenic recognition and tissue damage (106). A key enzyme in this process is phenoloxidase (PO), which mediates the oxidation of the amino acid tyrosine to dihydroxyphenylalanine (DOPA) and subsequently, the oxidation of DOPA and dopamine to their respective quinones which are precursors of brown/black eumelanin. PO is produced as prophenoloxidase (PPO) proenzyme which is converted to active PO by a clip domain serine proteinase. This cleavage generates ROS, giving immune melanization its cytotoxic activity.

Whereas the biochemical pathways downstream of PO are well-characterized, our knowledge of the molecular events leading to PPO activation are largely unelucidated (103). The involvement of Toll signaling in melanization responses has recently been demonstrated in adults (106). Hayan and SP7, two SPs acting upstream of Spätzle, activate PPO1 and PPO2, which were shown to be essential for effective resistance against several systemic fungal and G+ bacterial challenges $(106,107)$. Mutants for $P P O$ lack melanization, yet, maintained a dimorphic survival to $P$. rettgeri infection (23), suggesting that the activation of this immune response is not a driver of sex differences in survival to this particular pathogen. However, basal expression of some genes involved in melanogenesis are higher in males and a subset of these, including Dopa decarboxylase (Ddc) and yellow- $f$, respond transcriptionally to $P$. rettgeri infection (23). Alternative infection models where melanization is required to effectively control the infection may be more informative for understanding its potential roles in immune dimorphism. For example, the response of males and females to parasitoid wasp infection at larval stages has not been reported to our knowledge. Despite the importance of melanization for resistance to infection and injury, and the intersection of immunologic melanin production and Toll signaling, virtually no studies have assessed the sex-specific physiology of the response. Given that constitutive expression of Toll pathway genes, namely components upstream of Toll-1, as well as $D d c$, is greater in males (23), the hypothesis that males are more poised for melanization warrants testing.

\section{Systemic (Humoural) Immunity}

A number of studies have reported sex differences in systemic immunity (Figure 2). Systemic immunity is primarily driven by the fat body; however, expression levels of pathway components were largely measured in whole individuals. For example, following systemic challenge with $P$. rettgeri, males induced a number of Imd- and Toll-regulated effectors at higher level than females, paralleling their greater survivorship (23). Although to note, ablation of the Imd pathway does not suppress the sexual dimorphism in survival (23). Sex differences have repeatedly been found in expression and function of Toll pathway components. Females are reported to exhibit higher expression of Toll-1, the transmembrane receptor that activates the Toll intracellular signaling pathway (55), the Relish protein dorsal (74) and the Toll pathway component $n t f-2$ (75). The Toll pathway is known to be involved in two processes: dorso-ventral embryonic patterning, a female specific process occurring in the eggs, and in immunity. Signaling downstream of the transmembrane receptor Toll-1 is shared between these two processes. Thus, it is unsurprising that the apparent dimorphism in Toll pathway gene expression disappears once expression in the ovaries is excluded (23). Nonetheless, the expression of the Toll pathway seems crucial for the sexual dimorphism of many infections. This includes both G+ bacterial infection but, perhaps surprisingly, also Gbacterial infection (23). This occurs through the activation of the pathway by Persephone, a hemolymphatic serine protease, which senses microbial proteases during infection $(108,109)$. Toll-3, also called MstProx, shows male-specific expression and response to infection, which seems to be attributable to the gonads $(23,72)$. Toll-5, or Tehao, is also induced at higher levels in males than females following $P$. rettgeri infection (23). Toll-7, a plasma membrane Toll receptor that binds to viral glycoproteins, is expressed at higher basal levels in males $(23,55)$ and appears to have an additional, male-specific isoform (73).

Male-biased survival to $B$. bassiana also appears to be dependent on the Toll pathway, since mutations in Toll pathway components ablate or reverse the dimorphism (53). The induction of drosomycin and metchnikowin in the first $24 \mathrm{~h}$ of infection also tended to be greater in males (52). The survival dimorphism, however, was not suppressed when tested on spaetzle $(s p z)$ mutants, a component of the Toll pathway (52). These Toll-regulated dimorphisms may in part be mediated by expression of AMPs: for example, attacins and diptericins require functional Toll for full inducibility. Supporting this, the loss of Toll affects the Enterobacter cloacae-induced expression of attacins and diptericins more strongly in males (110), and males with a gain-of-function Toll mutation exhibit higher levels of the AMPs Cecropin A1 (CecA1), Diptericin A (DptA), Attacin $A$ (AttA), and Attacin B (AttB) in response to challenge (111). Furthermore, dimorphic induction of drosomycin in response to $P$. rettgeri infection is lost in $s p z$ mutants (23). Dimorphisms have also been reported in Imd pathway components, for example, several Imd-induced AMPs are found to be dimorphic in their expression levels. Using a construct with various diptericin promoter sequences upstream of the lac $Z$ gene, higher levels of induction were seen in females than males (79). In contrast, diptericin has been shown to be expressed at higher levels in unchallenged males than females, and is more strongly upregulated upon infection with the G- bacterium, $P$. carotovorum (24).

The JAnus Kinase protein and the Signal Transducer and Activator of Transcription (JAK-STAT) pathway, required for antiviral immune responses and induced upon bacterial infection, also shows dimorphic expression. G9a, a histone H3 lysine 9 methyltransferase, regulates tolerance to viral infection by regulating JAK/STAT (112) but in a sex-specific manner, with females being more sensitive to a loss of $G 9 a$ (113). In addition, the stress-responsive genes regulated by the Jak-Stat pathway, TurandotA, TurandotC, and TurandotM, were among the genes that were the most male-biased in an analysis of the transcriptional response to $P$. rettgeri infection (23), although the consequences of this are as yet unknown. Overall, males have a higher expression of many Toll- (and to a lesser extent Imd-) regulated genes. The reason for this dimorphism is unclear, but further work could investigate a potential link with the dual role for the Toll pathway in females. It is possible that the immune 
response via the Toll pathway in females is constrained by its consequences on egg development, a constraint which does not apply to males.

\section{Epithelial Immunity}

Comprising the third prominent arm of defense in D. melanogaster are the immune-reactive epidermal and epithelial barriers such as the cuticle, trachea, genitalia, and gut.

\section{Cuticle and Trachea}

Sex differences in defense against fungal inoculation of the cuticle with the entomopathogenic $B$. bassiana demonstrate femalebiased susceptibility $(53,114-116)$. Dimorphisms in cuticle integrity, or in immune responses of the cuticle or respiratory system could conceivably be underpinning this susceptibility. The trachea, which consist of airway epithelia and spiracles, is immunogenic, and responses may be activated by such cuticle inoculations. Studies that have assessed tracheal immunity in adults, thus far include only males $(71,117)$, rendering sexspecific responses within respiratory tissue another unexplored, potential contributor to dimorphic immunity. Dimorphisms in cuticular epithelial immune responses per se are also, to our knowledge, entirely unexplored.

\section{Genitalia and Gonads}

Male genitalia were found to be more primed for immune response to bacterial infection than that of females, where systemic and local AMP responses followed P. carotovorum inoculation of the genitalia in males (80). The female reproductive organs are also immune active, and were shown to constitutively express cecropin (66) and drosomycin (66-68), where drosomycin expression was found to be independent of Toll signaling in this tissue (67). Males exhibit constitutive expression of cecropin within the ejaculatory duct, independent of Relish signaling (68), suggesting that genital epithelia may circumvent classical pathways to activate AMPs. Immunogenicity of the reproductive tissues is evident from analyses of post-mating AMP responses in females $(118,119)$, and the antimicrobial protein transfer from male accessory gland and ejaculatory duct to the female (120). Andropin, an AMP unique to males, is also strongly upregulated in response to mating (69). RNA-seq analysis of $P$. rettgeri infected males and females, with and without gonads, illustrates the contribution made by reproductive tissue to systemic immune responses (23). Such comparative transcriptomics revealed male-biased defensin levels following infection to be gonad-dependent (23). It is an open question how much reproductive tissues contribute to systemic immunity; indeed it is unknown whether AMPs produced by the gonads are released into the hemolymph, or remain within the tissue.

\section{Malpighian Tubules}

Malpighian tubules (MT), epithelial organs dedicated to filtration and analogous to the mammalian kidney, are also immunogenic (121). Transcriptomic analysis of MT revealed differences in basal immune gene expression between the sexes (70); however, nothing is known about sexually dimorphic functions of MT or their contribution to immune dimorphisms.

\section{The Intestinal Epithelium}

The Drosophila gut is a major immune locus, responding to infection by producing AMPs and reactive oxygen species $(122,123)$. Infection-induced immune responses are observable in males (122); however, while a small number of studies have compared sex differences in gut metabolism (124), and physiology $(24,124-126)$, most work on intestinal immunity has focussed on females. Nothing is known about sex dimorphisms in AMP or ROS production, nor indeed survival, after oral infection. However, expression of several immunerelated genes have been reported. Nubbin, a transcription factor with two isoforms, $n u b-R B$ and $n u b-R D$ (127) regulates duration of immune responses within the gut. $N u b-R D$ mutants showed chronic immune activation in females (128), whilst overexpressing $n u b-R B$ resulted in a similar phenotype, illuminating their antagonistic roles within immune signaling (127). Overexpressing $n u b-R B$ within enterocytes and subsequent oral infection with $P$. carotovorum lead to total and $70 \%$ death in males and females, respectively, within $24 \mathrm{~h}$. Downregulation of $n u b-R B$ enhanced survival to challenge in males compared to controls, while having the opposite effect on females (127). Overexpressing $n u b-R B$ significantly reduced the lifespans of both sexes, conversely, males reared in germ-free conditions had a slightly enhanced median longevity compared to conventionally-reared counterparts (127). These data could potentially illustrate a greater susceptibility of males to immunopathology from both chronic immune activation and commensals. Nubbin isoform antagonism may also offer insight into dimorphic responses between the sexes, where expression of each may differ, however, the cited study only quantified isoform expression in males (127).

The luminal microbiome impacts intestinal immunity (123) as well as many other aspects of $D$. melanogaster physiology and behavior (129). This includes cellular immunity (130), and response to enteric viral infection (131). Studies have shown that the microbiota varies between the sexes in terms of load (24), composition (132), and effect on metabolic responses to diet (133). However, most studies assessing the gut microbiome have only analyzed females, and thus we have very little knowledge about the interaction of commensals with dimorphisms in intestinal immunity. Microbiota populations, at least of the two predominant genera Acetobacter and Lactobacillus, tend to increase over aging (134), and composition varies between the sexes, where aged males were reported to differ to a greater extent than aged females when compared to their younger counterparts (132). Aging is also associated with a loss of epithelial barrier integrity in the gut $(76,77,135)$. This phenomenon is more pronounced in females $(24,76)$, and is paralleled by increases in systemic immune activation, as indicated by systemic AMP levels (76). Microbiota dysbiosis (77) and loss of a tricellular junctional protein, Gliotactin (135), were shown to precede such changes in females, and loss of an intestinal septate junction protein, Snakeskin, exacerbates barrier loss and causes early death in both sexes (136). These data highlight the link between 
microbiome dysbiosis, maintenance of a stable gut barrier, and systemic inflammation. More work is needed to understand the interaction of the dimorphisms involved; for example, the apparently conflicting observations that the male microbiome shows greater changes (132), but despite this, the male gut barrier appears to be more stable over age (24). It is well-known that the microbiome is modeled by diet, environment, and host genotype, so comparing physiological data with microbiome data from different labs may confound interpretation.

\section{Aging and Immune Dimorphisms Aging and Inflammation}

Aging is known to be accompanied by heightened expression of immune genes (37, 39, 137-139). However, cause and consequence are difficult to separate, and understanding the contributions made by age to altered immunity, and immunity to aging, is challenging. When comparing the transcriptional response to aging in whole flies, a strong sex-by-age interaction was observed (139). Of the total significant probe sets, the majority were biased toward males, while just over $25 \%$ were sexually antagonistic. Included within this male-biased and antagonistic set were immune-related genes, such as the AMP, defensin (139).

In an experimental evolution study on lines where late-life fertility, and indirectly longevity, was selected for over 35 years, decreased expression of immune genes was strongly associated with increased lifespan (137). Females of longer-lived lines exhibited greater realized immunity in the face of challenge with P. carotovorum, B. bassiana, E. faecalis, and DCV than controls (137). Modulation of Toll components had varying effects on male and female lifespan: knockdown of the negative regulator cactus had a significantly reducing effect on lifespan, especially in males, whereas Toll and $s p z$ knockdown enhanced lifespan in both sexes (137). Dif knockdown had opposing outcomes between the sexes, with females experiencing a slight extension to lifespan (137). However, in two other studies, Dif mutants exhibited enhanced lifespan, in the context of intrinsically shortlived background lines (50, 140). Given the sex-specificity of Toll pathway gene expression seen in young flies (23), it is perhaps unsurprising that responses to such modulations are dimorphic.

Age-related systemic inflammation, for example, high basal levels of AMPs and ROS, has been assumed to negatively impact lifespan. This is supported by studies in which AMPs, or Rel-family transcription factors controlling their expression, have been manipulated. Both systemic and fat body-specific overexpression of relish negatively affected male lifespan to a greater extent than that of females, and relish male mutants were marginally longer-lived than females (39). The selective knockdown of relish at mid-life stages in the fat body, however, significantly extended lifespan in males (39). Global overexpression of attacin A, cecropin A1, defensin, and metchnikowin had significantly deleterious effects on lifespan of both sexes, with overexpression of defensin having a greater impact on males (39), reminiscent of the increase in defensin expression in aged males (139). This potentially illustrates age-related immunopathology, where the tempering of hyperactivated immune pathways at mid-late life stages is protective. Intriguingly, clean injury of the cuticle has been shown to extend lifespan in males only, suggesting that a nonlethal wound initiates a response that has a hormetic effect that is particularly effective in males (141). The mechanism for this is unknown, but it is tempting to speculate that it could initiate an anti-inflammatory state through induction of immune regulators.

\section{Immunosenescence}

Relatively few studies have looked at immune function in both sexes over aging, particularly from a mechanistic standpoint. While survival following $B$. bassiana decreases over aging in both sexes (140), systemic and cuticular inoculate challenge with the entomopathogenic fungus was reduced in aged females compared to young, while males succumbed only to cuticle inoculation, exhibiting a reduction solely in barrier integrity (114). Age negatively affected the ability to survive an oral $P$. carotovorum challenge in males compared to females, despite their comparatively superior maintenance of intestinal barrier integrity (24). In addition, aged males fared worse in response to systemic E. coli (142), P. aeruginosa, and Bacillus thuringiensis (22) challenges. The studies described above do not investigate the mechanisms underpinning these age-related immune dimorphisms, nor indeed the tissue(s) responsible, except via route of infection $(24,114)$. In a study investigating the effects of age on hemocyte function, hemocyte numbers were shown to decrease selectively in females over aging (21), supported by a recent study that only examined females (143); although both sexes maintained ex vivo phagocytic capacity over age (21). In contrast, a recent study found no effect of age on hemocyte number (22). It is clear that the mechanistic underpinnings of sex-by-age interactions in efficacy of immune responses and autoinflammation are undefined, but could be hugely informative to our understanding of sex differences in age-related pathology and lifespan.

\section{EVOLUTION OF DIMORPHISM THROUGH NATURAL SELECTION}

Males and females can have different life histories, which implies that they are exposed to different evolutionary pressures. Because the sexes share a genome, these different pressures can lead to sexual antagonism, which can potentially be resolved through the evolution of sex-specific regulation leading to phenotypic dimorphism. We explore this in the section below with reference to the immune system in Drosophila.

One possible driver of natural selection on dimorphism is unequal exposure to parasites in males and females. Males and females may differ in the habitats they occupy, their activity times, or their nutritional needs, for example. Males and females thus occupy separate niches and are potentially exposed to different parasites. Parasites can exert different selection pressures on males and females: the extent to which they do will depend on the extent of ecological divergence between the sexes. Knowledge of the ecology of wild Drosophila being relatively limited, it is difficult to define precisely which behaviors 
could cause such sex-specific selection. Females lay their eggs in rotting fruits, where they are necessarily exposed to a microberich environment. Whether males spend less time in these environments is not known. Lab studies have indicated that male and female Drosophila do not have the same optimal diet, and in diet choice experiments, make different nutritional selections in accordance with their role in reproduction (144-146). Males and females could potentially make different diet choices in the wild, and thus be exposed to different parasites.

A second possible driver of natural selection on dimorphism comes from the fact that the immune system allows resistance to parasites but also represents a cost: it requires a significant investment in terms of resources, and the activation of immune defenses can cause "collateral" damage [e.g., autoimmune reactions (147)]. From this it is predicted that hosts will evolve toward an immune response of intermediate intensity, and not toward a maximum response (148). In other words, hosts evolve within a framework of constraints corresponding to an evolving trade-off. But the terms of this trade-off are not necessarily the same for both sexes: Hamilton and Zuk proposed that the links between investment in immunity and life history traits are sexspecific (149). Under this assumption, it can be predicted that the optimal investment in immunity is not the same in males and females, and could even be antagonistic (150). This scenario is supported by evidence in Drosophila that both resistance and tolerance can be sexually antagonistic (46), that expression of immune genes is sexually dimorphic (27), and that the genetic architecture of many traits, including immunity, differ between males and females in Drosophila (151-153). This is supported by mutation accumulation experiments indicating that deleterious mutations do not have the same costs in both sexes (154156). Although the accumulation of spontaneous mutations in Drosophila has not yet been shown to have a sexually dimorphic cost on the immune response (46), it does appear have a sex-specific effect on fitness (156). If autosomal determination of immune traits are not clear-cut, the fact that Drosophila immune genes can be X- and Y-linked $(40,41,157)$ is sufficient to expect that genetic structure can affect immune system evolution in a sex-specific manner. First, the Y chromosome is, by definition, strictly under selection in males and has been demonstrated to influence the immune response $(41,157)$. For example, only males that had a Y-chromosome introduced from a single wild population differed in their ability to defend against S. marcescens (41). Second, since fathers do not pass an Xchromosome to their sons, evolution by sexual selection acting on males would be much slower for traits largely influenced by the $\mathrm{X}$ chromosome than would selection on autosomally determined traits, and X-linked sexually antagonistic traits would more freely affect sexual dimorphism (158). Supporting this is the demonstration of X-linked variation in immune response phenotypes in Drosophila, including bacterial load and immune gene expression, in a set of $168 \mathrm{X}$-chromosome extraction lines (40). Many of the associations of genetic variation with immune phenotype acted in a sex-specific or sexually antagonistic manner, supporting the theory that sexually antagonistic variation may be more easily maintained on the $\mathrm{X}$ chromosome, and this can impact dimorphism (158).

\section{Sexual Selection and Evolution of Dimorphism: The Hypothesis of the Susceptible Male}

Sexual selection is that which operates on the ability to mate successfully. Two traits that generally evolve in parallel in each sex under the effect of sexual selection are choice by females and the ornaments of males. Ornaments are expensive secondary sexual characteristics that evolve as a result of the selection made by the choice of females. A difficulty with this principle is that females can only choose males based on a trait that demonstrates their vigor if that trait remains variable. For sexual selection to occur, therefore, a continuous source of heritable genetic variation must be present in the population. This source of variation prevents genes for vigor from fixation and the character of choice to be only affected by non-heritable environmental factors. Parasites of all kinds offer such selective variation in value because they can evolve quickly and dynamically with their hosts $(149,159)$. It is on this basis that the famous hypothesis of William (Bill) Hamilton and Marlène Zuk was born. They proposed that parasite selection imposes the evolution of female choice for infection-resistant partners, which in turn favors the evolution of sexual dimorphism in hosts. Thus, as they observed in birds, a negative correlation between ornaments and parasitic load can be found in males (149). Such correlation between expensive ornamental traits and immunity may be present in Drosophila. One of the most clearly dimorphic characteristics in Drosophila is the color of the cuticle, which is darker in males than in females. The process of darkening the cuticle requires the production of eumelanin, which is also involved in the encapsulation of parasites. This dual role suggests that coloration and immunity are two related characteristics $(103,160)$. Furthermore, as mentioned above, melanin is produced from dopamine, a neurotransmitter also known to be involved in aggression behavior between males (161), male courtship for females (162) and female receptivity (163). Dopamine and melanin production are thus located at a metabolic crossroads establishing a link between secondary sexual characteristics, mating behavior, and immunity. Other visible, dimorphic characteristics in D. melanogaster include bristle number (abdominal and sternopleural), and the presence of sex combs, specialized leg bristles in males which aid copulation. Surprisingly, these traits have not been used, to our knowledge, to study sexual selection, despite being very clearly exposed to females. A recent study reported that flies with a mutation in the yellow gene, which encodes a protein involved in the synthesis of eumelanin, fail at mating because insufficient melanization renders their sex combs non-functional for grasping and mounting females during copulation (164). Furthermore, determination of bristle number in males is connected to the process of melanization (165). This link is confirmed by genetic analyses that have shown that $D d c$, an enzyme essential for dopamine synthesis, has a role in pigmentation (166), and also in the determination of the number of bristles (165). Interestingly, $D d c$ is expressed differentially in males and females, as expected, but its expression is modulated during a bacterial infection [see RNA-seq data for " $D d c$ " in (23)] (167). A mutation in the $d d c$ gene could therefore have an 
impact on both male ornamentation and response to infection. Female Drosophila are able to choose their mates on the basis of phenotypic traits $(168,169)$, and while evolutionary theory offers several different explanations for female mate choice, most include the evolution of heritable attractive features in males (170). The Drosophila Genetic Reference Panel (i.e., DGRP lines) show that natural populations indeed bear variation at several positions in the coding sequence of $D d c$ (see genome browser at genome.ucsc.edu). In Drosophila, it is unclear how male ornaments (or attractive traits) trade-off with investment in immunity, but one could speculate that factors required for both cuticle patterning and immune responses could be limiting. Since males have a high selection pressure for access to mating (25), they might still invest in their costly ornament (e.g., cuticle, bristles) to the detriment of their immunity. In any case, the hypothesis that investment in immune melanization may affect secondary sexual traits, such as bristles/combs, remains to be tested.

Hamilton and Zuk have shown that the dimorphism of investment in immunity increases with the intensity of sexual selection. This observation can be explained by a direct negative effect of reproductive traits on those of immunity: this is the socalled immunocompetence handicap hypothesis (171). It occurs because the immune system can interact directly with the hormonal system in relation to sexual dimorphism $(172,173)$. Increased production of hormones may thus have a benefit for secondary sexuality in males (e.g., ornaments, or competitive traits such as muscle mass) but a deleterious effect on the immune response. Since males have a high selection pressure for access to mating, they might invest in competitive traits to the detriment of their immunity (174). The handicap hypothesis implies that the resource allocation trade-offs between immunity and other characteristics related to selective value are not the same for males and females $(148,175,176)$, and leads to the conclusion that males should invest fewer resources in immunity than females. In males, the benefits of increased mating success through greater investment in sexually selected traits (or in costly behaviors) should offset the costs of disease-related reduction in lifespan. Females, on the other hand, would invest more in immunity than males to maximize their breeding time. This prediction extends Bateman's principle to immunity $(25,177)$. In Drosophila, the interaction between immunity and hormones has clearly been identified $(32,33,93,178)$. For example, females produce juvenile hormone $(\mathrm{JH})$ to lay fertilized eggs, and $\mathrm{JH}$ directly suppresses the immune response (93). JH affects the antimicrobial peptide (AMP) Drosomycin most strongly, which responds mainly to $\mathrm{G}+$ bacterial infection via the Toll-mediated immune pathway (32). Interestingly, as discussed above, a greater susceptibility of females to some infections is mediated by Toll signaling. This is suggestive that the sex-specific investment of females in egg production via the production of $\mathrm{JH}$ has a cost on their immune system, leading to sexual dimorphism in response to certain infections (23).

The previous hypotheses suggest that one sex should be superior than the other while facing infection. Although these hypotheses predict dimorphism per se, they cannot explain the inconsistencies in the direction it takes. Alternatively, sex-specific differences may arise from sex-specific changes in reproductive behavior in response to variation in fitness-limiting resources availability, and not from an intrinsically superior immune function (179). In such a case, sex-specific responses would be condition dependent. In D. melanogaster, availability of sexually receptive females is an important fitness-limiting resource. While males adjust their level of courtship in response to this resource, increased sexual activity reduces their immune functions, likely because of a reallocation of feeding time into the search for a mate (180). Food availability is, of course, a major fitness-limiting resource. When males and females were kept separate and given ad libitum food, immune function was maximized in both sexes and there was no sexual dimorphism in clearance of a benign infection with $E$. coli. However, when the fitness-limiting resources were scarce there was a sex-specific bias (179). When food was limited, females exhibited poorer clearance of the infection than males and, conversely, males with high sexual activity, despite abundant food, performed less well than females. Thus, if there are many reasons for dimorphism to evolve, there are many reasons for its direction to be plastic.

\section{Obstacles to the Evolution of Dimorphism}

If different selection pressures are applied to two subpopulations, there is every indication that they will evolve in different ways (181). However, males and females of a species are not subpopulations like any other, since their genomes must recombine in each generation. In each generation, therefore, a gene that is advantageous when expressed in a female can be transmitted from a mother to her son, in whom the expression of this gene could be disadvantageous. In summary, the evolution of a beneficial trait for one sex can be a burden for the other sex (182). In the previous example, the genetic origin of this burden is antagonistic pleiotropy: an allele beneficial to one sex has a negative effect on the other. This sexual conflict, highly investigated in Drosophila, can occur at one locus (intra-local conflict: a mutation at one locus has a positive effect for one sex but negative for the other) or at several (interlocal conflict: a mutation at one locus has a negative effect on one sex and selects a mutation at another locus that reduces the effectiveness of the first mutation) (26). This sexual antagonism could mean that the advantage obtained by one sex is exactly offset by the burden the other sex suffers. In other words, antagonistic pleiotropy could prevent the evolution of dimorphism. In a less extreme situation, if dimorphism manages to evolve despite pleiotropy, it is conceivable that neither sex will be able to adapt optimally.

\section{Dimorphism as a Resolution of Sexual Conflict}

It is also possible that selection may favor sex-specific regulatory genes that result in an advantageous allele in females being expressed only in females (183). Pleiotropy would then be eliminated, and dimorphism could evolve without constraint. To our knowledge, there is no experimental work that has studied the role of this sexual conflict in the evolution of sex-specific regulation of the response to infections in Drosophila. 


\section{One Pathogen, One Rule}

It is usually impossible to predict, for a given infectious disease, which sex will suffer the most. For example, in mammals, it is often said that males are the "susceptible" sex (184). Men are indeed more susceptible to leishmaniasis, malaria, or bilharzia; but they are more resistant to toxoplasmosis, amebiasis, and giardiasis $(12,185,186)$. The complexity increases considering that pathogens can adapt specifically to the sexspecific characteristics of the host. If a parasite is more often exposed to one sex, it is expected to adapt to that sex it encounters most frequently (187). Under such a scenario, even in the absence of sexual dimorphism in response to the infection, the parasite is expected to behave differently and to consequently induce a dimorphism in symptoms or virulence $(15,188)$. Attempts to generalize, through meta-analyses, are not consistent: they sometimes even imply that there is no real dimorphism (189). If the selection pressures applied to both sexes vary considerably from one parasite to another, we cannot exclude that the effects of the different parasites cancel each other out, so that the average selection pressures applied by all parasites ultimately lead to the same investment in immunity in males and females. Given that different parasites require different methods of control, this seems an unlikely outcome; instead, varied selection pressures, applied differently to each sex, requiring distinct responses, could result in a complex array of context-dependent dimorphisms. In Drosophila, reported directions of dimorphism in infection outcome are condition- and pathogen-dependent (Table 1), thus it seems inappropriate to propose a generality on the direction of immune sexual dimorphism $(23,40)$. However, even if the direction is difficult to predict, it is rare that dimorphism does not occur: in that sense, dimorphism in infection outcome seems to be the rule and not the exception.

\section{Environmental Effects on Immune Dimorphism}

As if pathogen-dependent dimorphism was not complex enough, infection almost certainly interacts with environmental factors to shape immune dimorphisms. Nutrition modifies the response to infection $(190,191)$, and where choice is offered, flies will change their feeding preferences in response to infection (192). Diet choices have been empirically demonstrated to increase fitness in insects (193), e.g., in a "true fruit fly" (Bactrocera tryoni)-S. marcescens infection model, where infection-induced selection of increased carbohydrate-to-protein ratio led to better survival (194). Baseline and infection-induced sex differences in nutrient preference may influence outcome to infection, as may dimorphic responses to macronutrients. For example, in a D. melanogaster-Vibrio cholerae infection model, increased levels of glucose selectively reduced lifespan in females, but delayed their succumbing to infection, whereas it had no effect on males (195), suggesting that while females suffer long-term consequences of chronically elevated insulin signaling, acute responses to pathogenic challenge, at least by $V$. cholerae, are enhanced by high dietary glucose (195). Nutrient-sensing pathways are known to regulate immune responses, among many other physiological responses to the environment (196), and perturbations in these pathways are shown to affect sex-differential gene expression in Drosophila, including expression of immune, defense, and stress response genes (146, 197). Thus, it is essential that we view diet, nutrient-sensing, and sex as interacting factors when considering immune dimorphisms.

Other biotic (density, competition), and abiotic (temperature, humidity) factors are likely to play into dimorphic outcomes to immune challenge. Indeed, in the wild, environmental inputs come as combined, covariate packages, and it is in the context of these combined inputs that Drosophila has evolved. Higher-order, systemic signaling pathways such as IIS/mTOR may integrate these inputs to produce phenotypically plastic responses that match current environmental states (196). IIS/mTOR has been empirically demonstrated to regulate immune responses in D. melanogaster (198, 199), suggesting that IIS/mTOR could represent a nexus for integrating sex differences in responses to environmental variation, including immunity. Among the biotic factors that have gained much attention recently is the microbiome. Diet, of course, contributes to modeling the gut microbiome and its sex-specificity might shape dimorphic bacterial communities. Thus, microbiotainfection interactions $(200,201)$ have the potential to shape immune dimorphisms. Microbiome sex differences have been demonstrated in Drosophila (132), and likely interact with both dietary choices (133) and responses to infection, therefore it follows that a full understanding of immune dimorphisms cannot be achieved without considering natural poly-microbial interactions.

\section{The Ubiquitous Endosymbiont Wolbachia as a Troublemaker}

Wolbachia is a ubiquitous endosymbiont predominantly transmitted by mothers to their offspring. This reproductive parasite is known to affect immune characteristics such as phenoloxidase (PO) activity (202), phagocytosis by hemocytes (203), and to affect the outcome of other infections, such as providing resistance to viral infection (204). While not the focus of the study, Martins et al. (60) showed that the level of resistance provided by Wolbachia status depends on the sex of the host. Furthermore, Wolbachia protects males more than females against enteric infection by the bacterium $P$. aeruginosa (205). For these reasons and because it is so common, we expect that Wolbachia infection could influence the direction of immune dimorphism, and even impact the evolution of the dimorphism itself.

\section{Regulation of Immune Dimorphism}

Immune dimorphisms in D. melanogaster arise from a shared genome, and must be a product of sex-specific gene regulation, however, this is not yet well-resolved. At the top of the regulatory hierarchy are genomic differences, namely sex chromosome karyotype. As we have discussed, there are clear $\mathrm{X}$ - and Y-linked effects on immunity in D. melanogaster. Downstream of karyotype, dimorphisms can be regulated by the sex determination pathway, a cascade of splicing factors regulated by $\mathrm{X}$ chromosome number that ultimately lead to 
the expression of sex-specific transcription factors (206). This pathway has recently been shown to have "non-canonical" routes of signaling in some tissues (125), and importantly, to exert profound effects on physiology in larvae and adults beyond its purely developmental role (20). However, the potential regulation of immunity by sex-specific pathways is as yet untested [but see (125) for transcriptional regulation in the intestinal epithelium].

Drosophila, and insects in general, demonstrate that sexual dimorphism can occur without the presence of sex steroids per se. Notably, insects produce the steroid hormones ecdysone and juvenile hormone $(\mathrm{JH})$, and as discussed, these are important regulators of immune function. It is possible that hormonal and genetic regulation interact; for example, via sex differences in hormone production or receptor expression (207). One potential source for dimorphic hormone production are the gonads, which may exert influences on immune responses in closely opposed organs, as has recently been demonstrated for regulation of intestinal carbohydrate metabolism by the testes (124). The tractability for genetic manipulation of sex-specific transcription factors and hormone production/reception is a major advantage to using D. melanogaster to better understand sex-specific regulation of immune function.

\section{CONCLUSION}

We understand relatively little about immune dimorphisms in Drosophila, despite their apparent prevalence and magnitude. A real gap in our knowledge is the physiological and mechanistic underpinnings of the male-female differences in survival to infection that have been widely reported. We know almost nothing about how sex dimorphisms are shaped over the life course, including during development, or the influence of dimorphic immunity on aging and vice versa. Dimorphisms may arise from fixed differences in gene expression and tissue function, or from more plastic mechanisms that respond to environmental variables, or both. One thing is certain: the interaction between sex and immunity is complex. Complexity does not lend itself to generalities, and therefore we must be cautious in stating rules about male or female responses. Sex is clearly an essential factor that must be considered in the interpretation of data arising from studies into immunity, where the ideal approach is to include both sexes wherever possible. We argue that not only will including both sexes in studies of Drosophila immunity give a more complete picture, it will offer valuable insight into fundamental mechanisms underpinning innate immunity and responses to infection, and an understanding of the factors that drive dimorphisms to arise.

\section{REFERENCES}

1. Jin W, Riley RM, Wolfinger RD, White KP, Passador-Gurgel G, Gibson G. The contributions of sex, genotype and age to transcriptional variance in Drosophila melanogaster. Nat Genet. (2001) 29:389-95. doi: 10.1038/ ng766

\section{AUTHOR CONTRIBUTIONS}

$\mathrm{RB}, \mathrm{M}-\mathrm{KC}, \mathrm{DD}$, and JR researched and wrote the manuscript. $\mathrm{DD}$ and JR planned and edited the manuscript. RB and $\mathrm{M}-\mathrm{KC}$ performed the literature survey and made the figures, graphs and tables.

\section{FUNDING}

M-KC was supported by funding to JR from the University of Edinburgh; RB was supported by a Darwin Trust Scholarship; DD was supported by the French Laboratory of Excellence project TULIP(ANR-10-LABX-41; ANR-11-IDEX0002-02).

\section{ACKNOWLEDGMENTS}

We thank the reviewers for their insightful and constructive comments on the manuscript.

\section{SUPPLEMENTARY MATERIAL}

The Supplementary Material for this article can be found online at: https://www.frontiersin.org/articles/10.3389/fimmu. 2019.03075/full\#supplementary-material

Figure S1 | Quantity of articles from "both" category with possible tag interactions. Total articles per tag are shown next to each tag title. If a tag is applied, it is indicated with a black dot. Black lines connecting dots indicates conditions where two or more tags were applied to the same article. Quantity of articles in each category are shown above the respective bar.

Table S1 | Complete analysis of 5,626 articles retrieved from webofknowledge.com search. The Boolean search was: (TS = ((infection OR immunity OR hemocyte OR imd OR toll) AND drosophila) NOT TI = (bug OR bumblebee OR shrimp OR damesfly OR mollusc OR crab OR squid OR beetle OR baculovirus OR ant OR monochamus OR dastarcus OR cockroach OR crickets OR gryllus OR bemisia OR armyworm OR spodoptera OR mussel OR galleria OR helicoverpa OR amphibian OR manduca OR bee OR honey OR bactrocera OR tenebrio OR zebra OR dugesia OR flesh OR Apis OR house OR glossnia OR jelly OR Andrias OR dragonfly OR pachydiplax OR termite OR leech OR stick OR rhynchophorus OR rhodnius OR pardosa OR plutella OR coleoptera OR zophobas OR glossina OR ceratitis OR suzukii OR diabrotica OR rootworm OR sheep OR whitefly OR bird OR branchiostoma OR lizards OR laodelphax OR ceratopogonidae OR crassostrea OR oyster OR artemia OR freshwater OR calliphoridae OR phytomonas OR acyrthosiphon OR aphid OR crustacean OR parhyale OR hippocampus OR seahorse OR anopheles OR protaetia OR sea OR litopenaeus OR copepod OR swine OR planthopper OR arabidopsis OR circulifer OR leafhopper OR apostichopus OR cryptolaemus OR clam OR paphia OR mollusk OR achaea OR castor OR musca OR salmon OR dog OR echinococcus OR hetaerina OR sarcophaga OR fleshfly OR bovine OR zygoptera OR calopterygidae OR coenagrionidae OR scorpion OR locusta OR harpalus OR culex OR scylla OR firefly OR honeybees OR antheraea OR penaeus OR trichinella OR prawn OR macrobrachium OR ostrinia OR arge OR magnaporthe OR Phaeotabanus OR palm OR ostrinia OR daphnia OR scallop OR Chlamys OR Biomphalaria OR pig OR Anostostomatidae OR Orthoptera OR crayfish OR procambarus OR Platynereis)).
2. Svensson EI, Goedert D, Gómez-Llano MA, Spagopoulou F, Nava-Bolaños A, Booksmythe I. Sex differences in local adaptation: what can we learn from reciprocal transplant experiments? Philos Trans R Soc B Biol Sci. (2018) 373:20170420. doi: 10.1098/rstb.2017.0420

3. Klein SL, Flanagan KL. Sex differences in immune responses. Nat Rev Immunol. (2016) 16:626-38. doi: 10.1038/nri.2016.90 
4. Simon V. Wanted: women in clinical trials. Science. (2005) 308:1517. doi: $10.1126 /$ science. 1115616

5. Beery AK, Zucker I. Sex bias in neuroscience and biomedical research. Neurosci Biobehav Rev. (2011) 35:565-572. doi: 10.1016/j.neubiorev.2010.07.002

6. Liu KA, DiPietro Mager NA. Women's involvement in clinical trials: historical perspective and future implications. Pharm Pract. (2016) 14:708. doi: 10.18549/PharmPract.2016.01.708

7. Mazure CM, Jones DP. Twenty years and still counting: including women as participants and studying sex and gender in biomedical research. BMC Womens Health. (2015) 15:94. doi: 10.1186/s12905-015-0251-9

8. Avery E, Clark J. Sex-related reporting in randomised controlled trials in medical journals. Lancet. (2016) 388:2839-40. doi: 10.1016/S0140-6736(16)32393-5

9. Clayton JA, Collins FS. Policy: NIH to balance sex in cell and animal studies. Nat News. (2014) 509:282. doi: 10.1038/509282a

10. Miller LR, Marks C, Becker JB, Hurn PD, Chen W-J, Woodruff T, et al. Considering sex as a biological variable in preclinical research. FASEB J. (2016) 31:29-34. doi: 10.1096/fj.201600781R

11. Guncay A, Balasubramaniam T, Plagens K, Weadge J, Long TAF. Cross-generational effects of male reproductive success and offspring immunocompetence in Drosophila melanogaster. FACETS. (2017) 2:34-52. doi: 10.1139/facets-2015-0007

12. vom Steeg LG, Klein SL. SeXX matters in infectious disease pathogenesis. PLoS Pathog. (2016) 12:e1005374. doi: 10.1371/journal.ppat.1005374

13. Reimchen TE, Nosil P. Ecological causes of sex-biased parasitism in threespine stickleback. Biol J Linn Soc. (2001) 73:51-63. doi: 10.1111/j.1095-8312.2001.tb01346.x

14. Kelly CD, Tawes BR. Sex-specific effect of juvenile diet on adult disease resistance in a field cricket. PLoS ONE. (2013) 8:e61301. doi: 10.1371/journal.pone.0061301

15. Duneau DF, Luijckx P, Ruder LF, Ebert D. Sex-specific effects of a parasite evolving in a female-biased host population. BMC Biol. (2012) 10:104. doi: 10.1186/1741-7007-10-104

16. Gipson SAY, Hall MD. Interactions between host sex and age of exposure modify the virulence-transmission trade-off. J Evol Biol. (2018) 31:428-437. doi: $10.1111 /$ jeb.13237

17. Kopp A, Duncan I, Carroll SB. Genetic control and evolution of sexually dimorphic characters in Drosophila. Nature. (2000) 408:553-9. doi: $10.1038 / 35046017$

18. Kolluru GR, Chappell MA, Zuk M. Sex differences in metabolic rates in field crickets and their dipteran parasitoids. J Comp Physiol B. (2004) 174:641-8. doi: 10.1007/s00360-004-0455-z

19. Teder T, Tammaru T. Sexual size dimorphism within species increases with body size in insects. Oikos. (2005) 108:321-34. doi: 10.1111/j.0030-1299.2005.13609.x

20. Millington JW, Rideout EJ. Sex differences in Drosophila development and physiology. Curr Opin Physiol. (2018) 6:46-56. doi: 10.1016/j.cophys.2018.04.002

21. Mackenzie DK, Bussière LF, Tinsley MC. Senescence of the cellular immune response in Drosophila melanogaster. Exp Gerontol. (2011) 46:8539. doi: 10.1016/j.exger.2011.07.004

22. Leech T, Evison SEF, Armitage SAO, Sait SM, Bretman A. Interactive effects of social environment, age and sex on immune responses in Drosophila melanogaster. J Evol Biol. (2019) 32:1082-92. doi: 10.1111/jeb.13509

23. Duneau DF, Kondolf HC, Im JH, Ortiz GA, Chow C, Fox MA, et al. The Toll pathway underlies host sexual dimorphism in resistance to both Gram-negative and Gram-positive bacteria in mated Drosophila. BMC Biol. (2017) 15:124. doi: 10.1186/s12915-0170466-3

24. Regan JC, Khericha M, Dobson AJ, Bolukbasi E, Rattanavirotkul N, Partridge L. Sex difference in pathology of the ageing gut mediates the greater response of female lifespan to dietary restriction. eLife. (2016) 5:10956. doi: 10.7554/eLife.10956

25. Bateman AJ. Intra-sexual selection in Drosophila. Heredity. (1948) 2:349-68.

26. Bonduriansky R, Chenoweth SF. Intralocus sexual conflict. Trends Ecol Evol. (2009) 24:280-8. doi: 10.1016/j.tree.2008.12.005
27. Innocenti $\mathrm{P}$, Morrow EH. The sexually antagonistic genes of Drosophila melanogaster. PLoS Biol. (2010) 8:e1000335. doi: 10.1371 /journal.pbio. 1000335

28. Tseng M. Sex-specific response of a mosquito to parasites and crowding. Proc $R$ Soc Lond B Biol Sci. (2004) 271:S186-8. doi: 10.1098/rsbl.2003.0139

29. Hoang KP, Teo TM, Ho TX, Le VS. Mechanisms of sex determination and transmission ratio distortion in Aedes aegypti. Parasit Vectors. (2016) 9:49. doi: 10.1186/s13071-016-1331-x

30. Xue L, Manore CA, Thongsripong P, Hyman JM. Two-sex mosquito model for the persistence of Wolbachia. J Biol Dyn. (2017) 11:216-37. doi: 10.1080/17513758.2016.1229051

31. Buchon N, Silverman N, Cherry S. Immunity in Drosophila melanogaster from microbial recognition to whole- organism physiology. Nat Rev Immunol. (2014) 14:796-810. doi: 10.1038/nri3763

32. Flatt T, Heyland A, Rus F, Porpiglia E, Sherlock C, Yamamoto R, et al. Hormonal regulation of the humoral innate immune response in Drosophila melanogaster. J Exp Biol. (2008) 211:2712-24. doi: 10.1242/jeb.014878

33. Regan JC, Brandão AS, Leitão AB, Mantas Dias ÂR, Sucena É, Jacinto A, et al. Steroid hormone signaling is essential to regulate innate immune cells and fight bacterial infection in Drosophila. PLoS Pathog. (2013) 9:e1003720. doi: 10.1371/journal.ppat.1003720

34. Bakalov VK, Gutin L, Cheng CM, Zhou J, Sheth P, Shah K, et al. Autoimmune disorders in women with turner syndrome and women with karyotypically normal primary ovarian insufficiency. J Autoimmun. (2012) 38:315-21. doi: 10.1016/j.jaut.2012.01.015

35. Hewagama A, Gorelik G, Patel D, Liyanarachchi P, Joseph McCune W, Somers E, et al. Overexpression of X-Linked genes in T cells from women with lupus. J Autoimmun. (2013) 41:60-71. doi: 10.1016/j.jaut.2012.12.006

36. Invernizzi P, Miozzo M, Selmi C, Persani L, Battezzati PM, Zuin M, et al. X chromosome monosomy: a common mechanism for autoimmune diseases. J Immunol. (2005) 175:575-8. doi: 10.4049/jimmunol.175.1.575

37. Kounatidis I, Chtarbanova S, Cao Y, Hayne M, Jayanth D, Ganetzky B, et al. NF- $\kappa$ B immunity in the brain determines fly lifespan in healthy aging and age-related neurodegeneration. Cell Rep. (2017) 19:836-48. doi: 10.1016/j.celrep.2017.04.007

38. Shukla AK, Spurrier J, Kuzina I, Giniger E. Hyperactive innate immunity causes degeneration of dopamine neurons upon altering activity of Cdk5. Cell Rep. (2019) 26:131-44.e4. doi: 10.1016/j.celrep.2018.12.025

39. Badinloo M, Nguyen E, Suh W, Alzahrani F, Castellanos J, Klichko VI, et al. Overexpression of antimicrobial peptides contributes to aging through cytotoxic effects in Drosophila tissues. Arch Insect Biochem Physiol. (2018) 98:e21464. doi: 10.1002/arch.21464

40. Hill-Burns EM, Clark AG. X-Linked variation in immune response in Drosophila melanogaster. Genetics. (2009) 183:1477-91. doi: 10.1534/genetics.108.093971

41. Kutch IC, Fedorka KM. Y-linked variation for autosomal immune gene regulation has the potential to shape sexually dimorphic immunity. Proc $R$ Soc B Biol Sci. (2015) 282:20151301. doi: 10.1098/rspb.2015.1301

42. Meier A, Chang JJ, Chan ES, Pollard RB, Sidhu HK, Kulkarni S, et al. Sex differences in the Toll-like receptor-mediated response of plasmacytoid dendritic cells to HIV-1. Nat Med. (2009) 15:955-9. doi: 10.1038/nm.2004

43. Akuffo H, Hultmark D, Engstöm A, Frohlich D, Kimbrell D. Drosophila antibacterial protein, cecropin A, differentially affects non-bacterial organisms such as Leishmania in a manner different from other amphipathic peptides. Int J Mol Med. (1998) 1:77-159.

44. Sinha P, Saxena SK. Changes in amine acid content in tomato as a result of infection with Rhizopus stolonifer in presence of Drosophila busckii. Sci Lett. (1988) 203.

45. Jeune B, Thomas-Orillard M. Beneficial effects of viral infection in Drosophila: an evolutionary model. Acta Oecol. (1991) 12:489-508.

46. Vincent CM, Sharp NP. Sexual antagonism for resistance and tolerance to infection in Drosophila melanogaster. Proc R Soc B Biol Sci. (2014) 281:20140987. doi: 10.1098/rspb.2014.0987

47. Schneider D, Miller WJ, Riegler M. Arthropods shopping for Wolbachia. In: Zchori-Fein E, Bourtzis K, editors. Manipulative Tenants Bacteria Associated with Arthropods. Boca Raton, FL: CRC Press-Taylor \& Francis Group (2011). p. 149-73. 
48. Palmer WH, Medd NC, Beard PM, Obbard DJ. Isolation of a natural DNA virus of Drosophila melanogaster, and characterisation of host resistance and immune responses. PLoS Pathog. (2018) 14:e1007050. doi: 10.1371/journal.ppat.1007050

49. Le Bourg É. Combined effects of suppressing live yeast and of a cold pretreatment on longevity, aging and resistance to several stresses in Drosophila melanogaster. Biogerontology. (2010) 11:245-54. doi: 10.1007/s10522-009-9250-2

50. Le Bourg E. The NF-kB like factor DIF has weaker effects on Drosophila melanogaster immune defenses than previously thought. J Comp Physiol B. (2011) 181:741-50. doi: 10.1007/s00360-011-0567-1

51. Le Bourg É. Fasting can protect young and middle-aged Drosophila melanogaster flies against a severe cold stress. Biogerontology. (2013) 14:51329. doi: 10.1007/s10522-013-9458-z

52. Taylor K, Kimbrell D. Host immune response and differential survival of the sexes in Drosophila. Fly. (2007) 1:197-204. doi: 10.4161/fly.5082

53. Shahrestani P, Chambers M, Vandenberg J, Garcia K, Malaret G, Chowdhury $\mathrm{P}$, et al. Sexual dimorphism in Drosophila melanogaster survival of Beauveria bassiana infection depends on core immune signaling. Sci Rep. (2018) 8:12501. doi: 10.1038/s41598-018-30527-1

54. Lu H-L, Wang JB, Brown MA, Euerle C, Leger RJS. Identification of Drosophila mutants affecting defense to an entomopathogenic fungus. Sci Rep. (2015) 5:12350. doi: 10.1038/srep12350

55. Chowdhury M, Li C-F, He Z, Lu Y, Liu X-S, Wang Y-F, et al. Toll family members bind multiple Spätzle proteins and activate antimicrobial peptide gene expression in Drosophila. J Biol Chem. (2019) 294:10172-81. doi: 10.1074/jbc.RA118.006804

56. Franchet A, Niehus S, Caravello G, Ferrandon D. Phosphatidic acid as a limiting host metabolite for the proliferation of the microsporidium Tubulinosema ratisbonensis in Drosophila flies. Nat Microbiol. (2019) 4:64555. doi: 10.1038/s41564-018-0344-y

57. Bastos RG, Howard ZP, Hiroyasu A, Goodman AG. Host and bacterial factors control susceptibility of Drosophila melanogaster to Coxiella burnetii infection. Infect Immun. (2017) 85:e00218-17. doi: 10.1128/IAI.00218-17

58. Kutch IC, Fedorka KM. A test for Y-linked additive and epistatic effects on surviving bacterial infections in Drosophila melanogaster. J Evol Biol. (2017) 30:1400-8. doi: 10.1111/jeb.13118

59. Gupta V, Stewart CO, Rund SSC, Monteith KM, Vale PF. Costs and benefits of sublethal Drosophila C virus infection. J Evol Biol. (2017) 30:1325-35. doi: 10.1111/jeb.13096

60. Martins NE, Faria VG, Nolte V, Schlötterer C, Teixeira L, Sucena É, et al. Host adaptation to viruses relies on few genes with different cross-resistance properties. Proc Natl Acad Sci USA. (2014) 111:5938-43. doi: 10.1073/pnas.1400378111

61. Vale PF, Jardine MD. Sex-specific behavioural symptoms of viral gut infection and Wolbachia in Drosophila melanogaster. J Insect Physiol. (2015) 82:28-32. doi: 10.1016/j.jinsphys.2015.08.005

62. Thomson TC, Schneemann A, Johnson J. Oocyte destruction is activated during viral infection. Genesis. (2012) 50:453-65. doi: 10.1002/dvg.22004

63. Gomariz-Zilber E, Jeune B, Thomas-Orillard M. Limiting conditions of the horizontal transmission of the Drosophila C virus in its host (D. melanogaster). Acta Oecol. (1998) 19:125-37. doi: 10.1016/S1146-609X(98)80016-7

64. Wayne ML, Blohm GM, Brooks ME, Regan KL, Brown BY, Barfield M, et al. The prevalence and persistence of sigma virus, a biparentally transmitted parasite of Drosophila melanogaster. Evol Ecol Res. (2011) 13:323-45.

65. Carpenter J, Hutter S, Baines JF, Roller J, Saminadin-Peter SS, Parsch J, et al. The transcriptional response of Drosophila melanogaster to infection with the sigma virus (Rhabdoviridae). PLoS ONE. (2009) 4:e6838. doi: 10.1371/journal.pone.0006838

66. Tzou P, Ohresser S, Ferrandon D, Capovilla M, Reichhart J-M, Lemaitre $\mathrm{B}$, et al. Tissue-specific inducible expression of antimicrobial peptide genes in Drosophila surface epithelia. Immunity. (2000) 13:737-48. doi: 10.1016/S1074-7613(00)00072-8

67. Ferrandon D, Jung AC, Criqui M-C, Lemaitre B, Uttenweiler-Joseph S, et al. A drosomycin-GFP reporter transgene reveals a local immune response in Drosophila that is not dependent on the toll pathway. EMBO J. (1998) 17:1217-27. doi: 10.1093/emboj/17.5.1217
68. Ryu J-H, Nam K-B, Oh C-T, Nam H-J, Kim S-H, Yoon J-H, et al. The homeobox gene caudal regulates constitutive local expression of antimicrobial peptide genes in Drosophila epithelia. Mol Cell Biol. (2004) 24:172-85. doi: 10.1128/MCB.24.1.172-185.2004

69. Samakovlis C, Kylsten P, Kimbrell DA, Engström A, Hultmark D. The andropin gene and its product, a male-specific antibacterial peptide in Drosophila melanogaster. EMBO J. (1991) 10:163-9. doi: 10.1002/j.1460-2075.1991.tb07932.x

70. Chintapalli VR, Terhzaz S, Wang J, Bratty MA, Watson DG, Herzyk P, et al. Functional correlates of positional and gender-specific renal asymmetry in Drosophila. PLoS ONE. (2012) 7:e32577. doi: 10.1371/journal.pone.0032577

71. Tang H, Kambris Z, Lemaitre B, Hashimoto C. A serpin that regulates immune melanization in the respiratory system of Drosophila. Dev Cell. (2008) 15:617-26. doi: 10.1016/j.devcel.2008.08.017

72. Levin TC, Malik HS. Rapidly evolving toll-3/4 genes encode malespecific toll-like receptors in Drosophila. Mol Biol Evol. (2017) 34:2307-23. doi: $10.1093 / \mathrm{molbev} / \mathrm{msx} 168$

73. Tauszig S, Jouanguy E, Hoffmann JA, Imler J-L. Toll-related receptors and the control of antimicrobial peptide expression in Drosophila. Proc Natl Acad Sci USA. (2000) 97:10520-5. doi: 10.1073/pnas.180130797

74. Reichhart JM, Georgel P, Meister M, Lemaitre B, Kappler C, Hoffmann JA. Expression and nuclear translocation of the rel/NF-kappa B-related morphogen dorsal during the immune response of Drosophila. Comptes Rendus Académie Sci Sér III Sci Vie. (1993) 316:1218-24.

75. Bhattacharya A, Steward R. The Drosophila homolog of NTF-2, the nuclear transport factor-2, is essential for immune response. EMBO Rep. (2002) 3:378-83. doi: 10.1093/embo-reports/kvf072

76. Rera M, Clark RI, Walker DW. Intestinal barrier dysfunction links metabolic and inflammatory markers of aging to death in Drosophila. Proc Natl Acad Sci USA. (2012) 109:21528-33. doi: 10.1073/pnas.1215 849110

77. Clark RI, Salazar A, Yamada R, Fitz-Gibbon S, Morselli M, Alcaraz J, et al. Distinct shifts in microbiota composition during drosophila aging impair intestinal function and drive mortality. Cell Rep. (2015) 12:1656-67. doi: 10.1016/j.celrep.2015.08.004

78. Vale PF, Jardine MD. Infection avoidance behavior: viral exposure reduces the motivation to forage in female Drosophila melanogaster. Fly. (2017) 11:3-9. doi: 10.1080/19336934.2016.1207029

79. Meister M, Braun A, Kappler C, Reichhart J-M, Hoffmann JA. Insect immunity. A transgenic analysis in Drosophila defines several functional domains in the diptericin promoter. EMBO J. (1994) 13:5958-66.

80. Gendrin M, Welchman DP, Poidevin M, Hervé M, Lemaitre B. Long-range activation of systemic immunity through peptidoglycan diffusion in Drosophila. PLoS Pathog. (2009) 5:e1000694. doi: 10.1371/journal.ppat.1000694

81. Le Bourg É. A cold stress applied at various ages can increase resistance to heat and fungal infection in aged Drosophila melanogaster flies. Biogerontology. (2011) 12:185-93. doi: 10.1007/s10522-010-9309-0

82. Bashir-Tanoli S, Tinsley MC. Immune response costs are associated with changes in resource acquisition and not resource reallocation. Funct Ecol. (2014) 28:1011-9. doi: 10.1111/1365-2435.12236

83. Wang JB, Lu H-L, Leger RJS. The genetic basis for variation in resistance to infection in the Drosophila melanogaster genetic reference panel. PLoS Pathog. (2017) 13:e1006260. doi: 10.1371/journal.ppat.1006260

84. Bourtzis K, O’Neill S. Wolbachia infections and arthropod reproduction Wolbachia can cause cytoplasmic incompatibility, parthenogenesis, and feminization in many arthropods. Bioscience. (1998) 48:287-93. doi: $10.2307 / 1313355$

85. Merçot H, Charlat S. Wolbachia infections in Drosophila Melanogaster and $D$. simulans: polymorphism and levels of cytoplasmic incompatibility. Genetica. (2004) 120:51-9. doi: 10.1023/B:GENE.0000017629.31383.8f

86. Cook PE, McGraw EA. Wolbachia pipientis: an expanding bag of tricks to explore for disease control. Trends Parasitol. (2010) 26:373-5. doi: 10.1016/j.pt.2010.05.006

87. Maistrenko OM, Serga SV, Vaiserman AM, Kozeretska IA. Effect of Wolbachia infection on aging and longevity-associated genes in Drosophila. In: Vaiserman AM, Moskalev AA, Pasyukova EG, editors. Life Extension: Lessons from Drosophila Healthy Ageing and 
Longevity. Cham: Springer International Publishing (2015). p. 83-104. doi: 10.1007/978-3-319-18326-8_4

88. Valanne S, Wang J-H, Rämet M. The Drosophila toll signaling pathway. $J$ Immunol. (2011) 186:649-56. doi: 10.4049/jimmunol.1002302

89. Myllymäki H, Valanne S, Rämet M. The Drosophila Imd signaling pathway. J Immunol. (2014) 192:3455-62. doi: 10.4049/jimmunol.1303309

90. Vaz F, Kounatidis I, Covas G, Parton RM, Harkiolaki M, Davis I, et al. Accessibility to peptidoglycan is important for the recognition of gram-positive bacteria in Drosophila. Cell Rep. (2019) 27:2480-92.e6. doi: 10.1016/j.celrep.2019.04.103

91. Buchanan JL, Meiklejohn CD, Montooth KL. Mitochondrial dysfunction and infection generate immunity-fecundity tradeoffs in Drosophila. Integr Comp Biol. (2018) 58:591-603. doi: 10.1093/icb/icy078

92. Short SM, Lazzaro BP. Female and male genetic contributions to post-mating immune defence in female Drosophila melanogaster. Proc R Soc B Biol Sci. (2010) 277:3649-57. doi: 10.1098/rspb.2010.0937

93. Schwenke RA, Lazzaro BP. Juvenile hormone suppresses resistance to infection in mated female Drosophila melanogaster. Curr Biol. (2017) 27:596601. doi: 10.1016/j.cub.2017.01.004

94. Yanagawa A, Guigue AMA, Marion-Poll F. Hygienic grooming is induced by contact chemicals in Drosophila melanogaster. Front Behav Neurosci. (2014) 8:254. doi: 10.3389/fnbeh.2014.00254

95. Yanagawa A, Chabaud M-A, Imai T, Marion-Poll F. Olfactory cues play a significant role in removing fungus from the body surface of Drosophila melanogaster. J Invertebr Pathol. (2018) 151:144-50. doi: 10.1016/j.jip.2017.11.011

96. Caragata EP, Real KM, Zalucki MP, McGraw EA. Wolbachia infection increases recapture rate of field-released Drosophila melanogaster. Symbiosis. (2011) 54:55. doi: 10.1007/s13199-011-0124-4

97. Toda H, Williams JA, Gulledge M, Sehgal A. A sleep-inducing gene, nemuri, links sleep and immune function in Drosophila. Science. (2019) 363:509. doi: 10.1126/science.aat1650

98. Howick VM, Lazzaro BP. Genotype and diet shape resistance and tolerance across distinct phases of bacterial infection. BMC Evol Biol. (2014) 14:56. doi: 10.1186/1471-2148-14-56

99. Kurz CL, Charroux B, Chaduli D, Viallat-Lieutaud A, Royet J. Peptidoglycan sensing by octopaminergic neurons modulates Drosophila oviposition. Elife. (2017) 6:e21937. doi: 10.7554/eLife.21937

100. Masuzzo A, Manière G, Viallat-Lieutaud A, Avazeri É, Zugasti O, Grosjean $\mathrm{Y}$, et al. Peptidoglycan-dependent NF- $\kappa \mathrm{B}$ activation in a small subset of brain octopaminergic neurons controls female oviposition. eLife. (2019) 8:e50559. doi: 10.7554/eLife.50559

101. Kelsey EM, Luo X, Brückner K, Jasper H. Schnurri regulates hemocyte function to promote tissue recovery after DNA damage. J Cell Sci. (2012) 125:1393-400. doi: 10.1242/jcs. 095323

102. Kleinhesselink K, Conway C, Sholer D, Huang I, Kimbrell DA. Regulation of hemocytes in Drosophila requires dappled Cytochrome b5. Biochem Genet. (2011) 49:329-51. doi: 10.1007/s10528-010-9411-7

103. Nakhleh J, El Moussawi L, Osta MA. The melanization response in insect immunity. In: Ligoxygakis P. editor. Advances in Insect Physiology. Elsevier (2017). p. 83-109.

104. Nappi AJ, Poirié M, Carton Y. Chapter 4: The role of melanization and cytotoxic by-products in the cellular immune responses of Drosophila against parasitic wasps. In: Prevost G. editor. Advances in Parasitology. Elsevier (2009). p. 99-121. doi: 10.1016/S0065-308X(09)70004-1

105. Dudzic J, Kondo S, Ueda R, Bergman CM, Lemaitre B. Drosophila innate immunity: regional and functional specialization of prophenoloxidases. BMC Biol. (2015) 13:81. doi: 10.1186/s12915-015-0193-6

106. Dudzic J, Hanson MA, Iatsenko I, Kondo S, Lemaitre B. More than black or white: melanization and toll share regulatory serine proteases in Drosophila. Cell Rep. (2019) 27:1050-61.e3. doi: 10.1016/j.celrep.2019.03.101

107. Binggeli O, Neyen C, Poidevin M, Lemaitre B. Prophenoloxidase activation is required for survival to microbial infections in Drosophila. PLoS Pathog. (2014) 10:e1004067. doi: 10.1371/journal.ppat.1004067

108. Ming M, Obata F, Kuranaga E, Miura M. Persephone/Spätzle pathogen sensors mediate the activation of Toll receptor signaling in response to endogenous danger signals in apoptosis-deficient Drosophila. J Biol Chem. (2014) 289:7558-68. doi: 10.1074/jbc.M113.543884
109. Issa N, Guillaumot N, Lauret E, Matt N, Schaeffer-Reiss C, Dorsselaer $\mathrm{AV}$, et al. The circulating protease persephone is an immune sensor for microbial proteolytic activities upstream of the Drosophila toll pathway. Mol Cell. (2018) 69:539-50.e6. doi: 10.1016/j.molcel.2018. 01.029

110. Hedengren M, Borge K, Hultmark D. Expression and evolution of the drosophila attacin/diptericin gene family. Biochem Biophys Res Commun. (2000) 279:574-81. doi: 10.1006/bbrc.2000.3988

111. Junell A, Uvell H, Davis MM, Edlundh-Rose E, Antonsson A, Pick L, Engström Y. The POU transcription factor drifter/ventral veinless regulates expression of Drosophila immune defense genes. Mol Cell Biol. (2010) 30:3672-84. doi: 10.1128/MCB.00223-10

112. Merkling SH, Bronkhorst AW, Kramer JM, Overheul GJ, Schenck $\mathrm{A}, \mathrm{Rij} \mathrm{RPV}$. The epigenetic regulator G9a mediates tolerance to RNA virus infection in Drosophila. PLoS Pathog. (2015) 11:e1004692. doi: 10.1371/journal.ppat.1004692

113. Gupta, Vale PF. Nonlinear disease tolerance curves reveal distinct components of host responses to viral infection. R Soc Open Sci. (2017) 4:170342. doi: 10.1098/rsos.170342

114. Kubiak M, Tinsley MC. Sex-specific routes to immune senescence in Drosophila melanogaster. Sci Rep. (2017) 7:10417. doi: 10.1038/s41598-017-11021-6

115. Le Bourg É, Massou I, Gobert V. Cold stress increases resistance to fungal infection throughout life in Drosophila melanogaster. Biogerontology. (2008) 10:613. doi: 10.1007/s10522-008-9206-y

116. Le Rohellec M, Le Bourg É. Contrasted effects of suppressing live yeast from food on longevity, aging and resistance to several stresses in Drosophila melanogaster. Exp Gerontol. (2009) 44:695-707. doi: 10.1016/j.exger.2009.08.001

117. Akhouayri I, Turc C, Royet J, Charroux B. Toll-8/Tollo negatively regulates antimicrobial response in the Drosophila respiratory epithelium. PLoS Pathog. (2011) 7:e1002319. doi: 10.1371/journal.ppat.1002319

118. Peng J, Zipperlen P, Kubli E. Drosophila sex-peptide stimulates female innate immune system after mating via the Toll and Imd pathways. Curr Biol. (2005) 15:1690-94. doi: 10.1016/j.cub.2005.08.048

119. Winterhalter WE, Fedorka KM. Sex-specific variation in the emphasis, inducibility and timing of the post-mating immune response in Drosophila melanogaster. Proc R Soc B Biol Sci. (2009) 276:1109-17. doi: $10.1098 /$ rspb.2008.1559

120. Lung O, Kuo L, Wolfner MF. Drosophila males transfer antibacterial proteins from their accessory gland and ejaculatory duct to their mates. $J$ Insect Physiol. (2001) 47:617-22. doi: 10.1016/S0022-1910(00)00151-7

121. McGettigan J, McLennan RKJ, Broderick KE, Kean L, Allan AK, Cabrero P, et al. Insect renal tubules constitute a cell-autonomous immune system that protects the organism against bacterial infection. Insect Biochem Mol Biol. (2005) 35:741-54. doi: 10.1016/j.ibmb.2005.02.017

122. Ha E-M, Oh C-T, Bae YS, Lee W-J. A direct role for dual oxidase in Drosophila gut immunity. Science. (2005) 310:847-50. doi: $10.1126 /$ science. 1117311

123. Buchon N, Broderick NA, Lemaitre B. Gut homeostasis in a microbial world: insights from Drosophila melanogaster. Nat Rev Microbiol. (2013) 11:615-26. doi: $10.1038 /$ nrmicro3074

124. Hudry B, de Goeij E, Mineo A, Gaspar P, Hadjieconomou D, Studd C, et al. Sex differences in intestinal carbohydrate metabolism promote food intake and sperm maturation. Cell. (2019) 178:901-18.e16. doi: 10.1016/j.cell.2019.07.029

125. Hudry B, Khadayate S, Miguel-Aliaga I. The sexual identity of adult intestinal stem cells controls organ size and plasticity. Nature. (2016) 530:344-8. doi: 10.1038/nature16953

126. Regan JC, Lu Y-X, Bolukbasi E, Khericha M, Partridge L. Ras inhibition by trametinib treatment in Drosophila attenuates gut pathology in females and extends lifespan in both sexes. bioRxiv. (2018) 356295. doi: 10.1101/356295

127. Lindberg BG, Tang X, Dantoft W, Gohel P, Esfahani SS, Lindvall JM, Engström Y. Nubbin isoform antagonism governs Drosophila intestinal immune homeostasis. PLoS Pathog. (2018) 14:e1006936. doi: 10.1371/journal.ppat.1006936

128. Dantoft W, Davis MM, Lindvall JM, Tang X, Uvell H, Junell A, et al. The Oct1 homolog Nubbin is a repressor of NF-kB-dependent immune gene 
expression that increases the tolerance to gut microbiota. BMC Biol. (2013) 11:99. doi: 10.1186/1741-7007-11-99

129. Martino M, Ma D, Leulier F. Microbial influence on Drosophila biology. Curr Opin Microbiol. (2017) 38:165-70. doi: 10.1016/j.mib.2017.06.004

130. Benoit JB, Vigneron A, Broderick NA, Wu Y, Sun JS, Carlson JR, et al. Symbiont-induced odorant binding proteins mediate insect host hematopoiesis. elife. (2017) 6:e19535. doi: 10.7554/eLife.19535

131. Sansone CL, Cohen J, Yasunaga A, Xu J, Osborn G, Subramanian $\mathrm{H}$, et al. Microbiota-dependent priming of antiviral intestinal immunity in Drosophila. Cell Host Microbe. (2015) 18:571-81. doi: 10.1016/j.chom.2015.10.010

132. Han G, Lee HJ, Jeong SE, Jeon CO, Hyun S. Comparative analysis of Drosophila melanogaster gut microbiota with respect to host strain, sex, and age. Microb Ecol. (2017) 74:207-16. doi: 10.1007/s00248-016-0925-3

133. Wong AC-N, Dobson AJ, Douglas AE. Gut microbiota dictates the metabolic response of Drosophila to diet. J Exp Biol. (2014) 217:1894-901. doi: 10.1242/jeb.101725

134. Blum JE, Fischer CN, Miles J, Handelsman J. Frequent replenishment sustains the beneficial microbiome of Drosophila melanogaster. mBio. (2013) 4:e00860-13. doi: 10.1128/mBio.00860-13

135. Resnik-Docampo M, Koehler CL, Clark RI, Schinaman JM, Sauer V, Wong $\mathrm{DM}$, et al. Tricellular junctions regulate intestinal stem cell behaviour to maintain homeostasis. Nat Cell Biol. (2017) 19:52-9. doi: 10.1038/ncb3454

136. Salazar AM, Resnik-Docampo M, Ulgherait M, Clark RI, Shirasu-Hiza $\mathrm{M}$, Jones DL, et al. Intestinal snakeskin limits microbial dysbiosis during aging and promotes longevity. iScience. (2018) 9:229-43. doi: 10.1016/j.isci.2018.10.022

137. Fabian DK, Garschall K, Klepsatel P, Santos-Matos G, Sucena É, Kapun M, et al. Evolution of longevity improves immunity in Drosophila. Evol Lett. (2018) 2:567-79. doi: 10.1002/evl3.89

138. Odnokoz O, Nakatsuka K, Klichko VI, Nguyen J, Solis LC, Ostling K, et al. Mitochondrial peroxiredoxins are essential in regulating the relationship between Drosophila immunity and aging. Biochim Biophys Acta Mol Basis Dis. (2017) 1863:68-80. doi: 10.1016/j.bbadis.2016.10.017

139. Wilson RH, Lai CQ, Lyman RF, Mackay TFC. Genomic response to selection for postponed senescence in Drosophila. Mech Ageing Dev. (2013) 134:79-88. doi: 10.1016/j.mad.2012.11.003

140. Le Bourg É, Malod K, Massou I. The NF-кB-like factor DIF could explain some positive effects of a mild stress on longevity, behavioral aging, and resistance to strong stresses in Drosophila melanogaster. Biogerontology. (2012) 13:445-55. doi: 10.1007/s10522-012-9389-0

141. Henten AMV, Loeschcke V, Pedersen JG, Leisner JJ, Sarup P. Injuries can prolong lifespan in Drosophila melanogaster males. Biogerontology. (2016) 17:337-46. doi: 10.1007/s10522-015-9616-6

142. Ramsden S, Cheung YY, Seroude L. Functional analysis of the Drosophila immune response during aging. Aging Cell. (2008) 7:225-36. doi: 10.1111/j.1474-9726.2008.00370.x

143. Sanchez Bosch P, Makhijani K, Herboso L, Gold KS, Baginsky R, Woodcock $\mathrm{KJ}$, et al. Adult Drosophila lack hematopoiesis but rely on a blood cell reservoir at the respiratory epithelia to relay infection signals to surrounding tissues. Dev Cell. (2019) 51:787-803. doi: 10.1016/j.devcel.2019. 10.017

144. Camus MF, Fowler K, Piper MW, Reuter M. Sex and genotype effects on nutrient-dependent fitness landscapes in Drosophila melanogaster. Proc R Soc B Biol Sci. (2017) 284:20172237. doi: 10.1098/rspb.2017.2237

145. Camus MF, Huang C-C, Reuter M, Fowler K. Dietary choices are influenced by genotype, mating status, and sex in Drosophila melanogaster. Ecol Evol. (2018) 8:5385-93. doi: 10.1002/ece3.4055

146. Camus MF, Piper MD, Reuter M. Sex-specific transcriptomic responses to changes in the nutritional environment. eLife. (2019) 8:e47262. doi: $10.7554 /$ eLife.47262

147. Amur S, Parekh A, Mummaneni P. Sex differences and genomics in autoimmune diseases. J Autoimmun. (2012) 38:J254-65. doi: 10.1016/j.jaut.2011.12.001

148. Zuk M, Stoehr AM. Immune defense and host life history. Am Nat. (2002) 160:S9-22. doi: 10.1086/342131

149. Hamilton WD, Zuk M. Heritable true fitness and bright birds: a role for parasites? Science. (1982) 218:384-7. doi: 10.1126/science.7123238
150. Remolina SC, Chang PL, Leips J, Nuzhdin SV, Hughes KA. Genomic basis of aging and life-history evolution in Drosophila Melanogaster. Evolution. (2012) 66:3390-403. doi: 10.1111/j.1558-5646.2012.01710.x

151. Cowley DE, Atchley WR. Quantitative genetics of Drosophila Melanogaster. II. Heritabilities and genetic correlations between sexes for head and thorax traits. Genetics. (1988) 119:421-33.

152. Cowley DE, Atchley WR, Rutledge JJ. Quantitative genetics of Drosophila Melanogaster. I. Sexual dimorphism in genetic parameters for wing traits. Genetics. (1986) 114:549-66.

153. Mackay TFC. The genetic architecture of quantitative traits. Annu Rev Genet. (2001) 35:303-39. doi: 10.1146/annurev.genet.35.102401.090633

154. Mallet MA, Chippindale AK. Inbreeding reveals stronger net selection on Drosophila melanogaster males: implications for mutation load and the fitness of sexual females. Heredity. (2011) 106:994-1002. doi: $10.1038 /$ hdy.2010.148

155. Morrow EH, Stewart AD, Rice WR. Assessing the extent of genome-wide intralocus sexual conflict via experimentally enforced gender-limited selection. J Evol Biol. (2008) 21:1046-54. doi: 10.1111/j.1420-9101.2008.01542.x

156. Sharp NP, Agrawal AF. Male-biased fitness effects of spontaneous mutations in Drosophila Melanogaster. Evolution. (2013) 67:1189-95. doi: 10.1111/j.1558-5646.2012.01834.x

157. Lemos B, Branco AT, Hartl DL. Epigenetic effects of polymorphic Y chromosomes modulate chromatin components, immune response, and sexual conflict. Proc Natl Acad Sci USA. (2010) 107:15826-31. doi: $10.1073 /$ pnas. 1010383107

158. Rice WR. Sex chromosomes and the evolution of sexual dimorphism. Evolution. (1984) 38:735-42. doi: 10.1111/j.1558-5646.1984.tb00346.x

159. Eshel I, Hamilton WD. Parent-offspring correlation in fitness under fluctuating selection. Proc R Soc Lond B Biol Sci. (1984) 222:1-14. doi: $10.1098 / \mathrm{rspb} .1984 .0046$

160. Andersen SO. Insect cuticular sclerotization: a review. Insect Biochem Mol Biol. (2010) 40:166-78. doi: 10.1016/j.ibmb.2009.10.007

161. Alekseyenko OV, Chan Y-B, Li R, Kravitz EA. Single dopaminergic neurons that modulate aggression in Drosophila. Proc Natl Acad Sci USA. (2013) 110:6151-6. doi: 10.1073/pnas.1303446110

162. Neckameyer WS. Dopamine and mushroom bodies in Drosophila: experience-dependent and -independent aspects of sexual behavior. Learn Mem. (1998) 5:157-65. doi: 10.1101/lm.5.1.157

163. Neckameyer WS. Dopamine modulates female sexual receptivity in Drosophila Melanogaster. J Neurogenet. (1998) 12:101-14. doi: 10.3109/01677069809167259

164. Massey JH, Chung D, Siwanowicz I, Stern DL, Wittkopp PJ. The yellow gene influences Drosophila male mating success through sex comb melanization. eLife. (2019) 8:e49388. doi: 10.7554/eLife.49388

165. Mackay TFC, Lyman RF. Drosophila bristles and the nature of quantitative genetic variation. Philos Trans R Soc B Biol Sci. (2005) 360:1513-27. doi: $10.1098 /$ rstb.2005.1672

166. Anh NTT, Nishitani M, Harada S, Yamaguchi M, Kamei K. Essential role of duox in stabilization of Drosophila wing. J Biol Chem. (2011) 286:33244-51. doi: $10.1074 /$ jbc.M111.263178

167. Davis MM, Primrose DA, Hodgetts RB. A member of the p38 mitogenactivated protein kinase family is responsible for transcriptional induction of Dopa decarboxylase in the epidermis of Drosophila melanogaster during the innate immune response. Mol Cell Biol. (2008) 28:4883-95. doi: 10.1128/MCB.02074-07

168. Danchin E, Nöbel S, Pocheville A, Dagaeff A-C, Demay L, Alphand $\mathrm{M}$, et al. Cultural flies: conformist social learning in fruitflies predicts long-lasting mate-choice traditions. Science. (2018) 362:1025-30. doi: 10.1126/science.aat 1590

169. Mery F, Varela SAM, Danchin É, Blanchet S, Parejo D, Coolen I, et al. Public versus personal information for mate copying in an invertebrate. Curr Biol. (2009) 19:730-4. doi: 10.1016/j.cub.2009.02.064

170. Friberg U, Arnqvist G. Fitness effects of female mate choice: preferred males are detrimental for Drosophila melanogaster females. J Evol Biol. (2003) 16:797-811. doi: 10.1046/j.1420-9101.2003.00597.x

171. Folstad I, Karter AJ. Parasites, bright males, and the immunocompetence handicap. Am Nat. (1992) 139:603-22. 
172. Foo YZ, Nakagawa S, Rhodes G, Simmons LW. The effects of sex hormones on immune function: a meta-analysis. Biol Rev. (2017) 92:551-71. doi: $10.1111 /$ brv. 12243

173. Grossman CJ. Interactions between the gonadal steroids and the immune system. Science. (1985) 227:257-61. doi: 10.1126/science.3871252

174. Moore SL, Wilson K. Parasites as a viability cost of sexual selection in natural populations of mammals. Science. (2002) 297:2015-8. doi: 10.1126/science.1074196

175. Nunn CL, Lindenfors P, Pursall ER, Rolff J. On sexual dimorphism in immune function. Philos Trans R Soc B Biol Sci. (2009) 364:61-9. doi: $10.1098 /$ rstb. 2008.0148

176. Zuk M. Reproductive strategies and disease susceptibility: an evolutionary viewpoint. Parasitol Tdy. (1990) 6:231-3. doi: 10.1016/0169-4758(90)90202-F

177. Rolff J. Bateman's principle and immunity. Proc R Soc Lond B Biol Sci. (2002) 269:867-72. doi: 10.1098/rspb.2002.1959

178. Rus F, Flatt T, Tong M, Aggarwal K, Okuda K, Kleino A, et al. Ecdysone triggered PGRP-LC expression controls Drosophila innate immunity. EMBO J. (2013) 32:1626-38. doi: 10.1038/emboj.2013.100

179. McKean KA, Nunney L. Bateman's principle and immunity: phenotypically plastic reproductive strategies predict changes in immunological sex differences. Evolution. (2005) 59:1510-7. doi: 10.1554/04-657

180. McKean KA, Nunney L. Increased sexual activity reduces male immune function in Drosophila melanogaster. Proc Natl Acad Sci USA. (2001) 98:7904-9. doi: 10.1073/pnas.131216398

181. Fisher RA. The Genetical Theory of Natural Selection. Oxford, UK: Oxford University Press (1930).

182. Lande R. Sexual dimorphism, sexual selection, and adaptation in polygenic characters. Evolution. (1980) 34:292-305. doi: 10.1111/j.1558-5646.1980.tb04817.x

183. Connallon T, Knowles LL. Intergenomic conflict revealed by patterns of sex-biased gene expression. Trends Genet. (2005) 21:495-9. doi: 10.1016/j.tig.2005.07.006

184. Zuk M. The sicker sex. PLoS Pathog. (2009) 5:e1000267. doi: 10.1371/journal.ppat.1000267

185. Klein SL. Hormonal and immunological mechanisms mediating sex differences in parasite infection. Parasite Immunol. (2004) 26:247-64. doi: 10.1111/j.0141-9838.2004.00710.x

186. Perch M, Sodemann M, Jakobsen MS, Valentiner-Branth P, Steinsland H, Fischer TK, et al. Seven years' experience with Cryptosporidium parvum in Guinea-Bissau, West Africa. Ann Trop Paediatr. (2001) 21:313-8. doi: 10.1080/07430170120093490

187. Duneau DF, Ebert D. Host sexual dimorphism and parasite adaptation. PLoS Biol. (2012) 10:e1001271. doi: 10.1371/journal.pbio.1001271

188. Úbeda F, Jansen VA. The evolution of sex-specific virulence in infectious diseases. Nat Commun. (2016) 7:13849. doi: 10.1038/ncomms13849

189. Kelly CD, Stoehr AM, Nunn C, Smyth KN, Prokop ZM. Sexual dimorphism in immunity across animals: a meta-analysis. Ecol Lett. (2018) 21:1885-94. doi: 10.1111/ele.13164

190. Serbus LR, White PM, Silva JP, Rabe A, Teixeira L, Albertson R, et al. The impact of host diet on Wolbachia titer in Drosophila. PLoS Pathog. (2015) 11:e1004777. doi: 10.1371/journal.ppat.1004777

191. Ponton F, Wilson K, Holmes A, Raubenheimer D, Robinson KL, Simpson SJ. Macronutrients mediate the functional relationship between Drosophila and Wolbachia. Proc R Soc B Biol Sci. (2015) 282:20142029. doi: 10.1098/rspb.2014.2029

192. Ponton F, Morimoto J, Robinson K, Kumar SS, Cotter S, Wilson K, et al. Macronutrients modulate resistance to infection and immunity in Drosophila. bioRxiv. (2018) 498493. doi: 10.1101/498493

193. Anagnostou C, LeGrand EA, Rohlfs M. Friendly food for fitter flies? - Influence of dietary microbial specieson food choice and parasitoid resistance in Drosophila. Oikos. (2010) 119:533-41. doi: 10.1111/j.1600-0706.2009.18001.x

194. Dinh H, Mendez V, Tabrizi ST, Ponton F. Macronutrients and infection in fruit flies. Insect Biochem Mol Biol. (2019) 110:98-104. doi: 10.1016/j.ibmb.2019.05.002

195. Galenza A, Hutchinson J, Campbell SD, Hazes B, Foley E. Glucose modulates Drosophila longevity and immunity independent of the microbiota. Biol Open. (2016) 5:165-73. doi: 10.1242/bio.015016

196. Regan JC, Froy H, Walling CA, Moatt JP, Nussey DH. Dietary restriction and insulin-like signalling pathways as adaptive plasticity: a synthesis and re-evaluation. Funct Ecol. (2019) 34. doi: 10.1111/1365-2435.13418

197. Graze RM, Tzeng R-Y, Howard TS, Arbeitman MN. Perturbation of IIS/TOR signaling alters the landscape of sex-differential gene expression in Drosophila. BMC Genomics. (2018) 19:893. doi: 10.1186/s12864-018-5308-3

198. DiAngelo JR, Bland ML, Bambina S, Cherry S, Birnbaum MJ. The immune response attenuates growth and nutrient storage in Drosophila by reducing insulin signaling. Proc Natl Acad Sci USA. (2009) 106:20853-8. doi: 10.1073/pnas.0906749106

199. Karpac J, Younger A, Jasper H. Dynamic coordination of innate immune signaling and insulin signaling regulates systemic responses to localized DNA damage. Dev Cell. (2011) 20:841-54. doi: 10.1016/j.devcel.2011.05.011

200. Weiss BL, Wang J, Maltz MA, Wu Y, Aksoy S. Trypanosome infection establishment in the tsetse fly gut is influenced by microbiomeregulated host immune barriers. PLoS Pathog. (2013) 9:e1003318. doi: 10.1371/journal.ppat.1003318

201. Jupatanakul N, Sim S, Dimopoulos G. The insect microbiome modulates vector competence for arboviruses. Viruses. (2014) 6:4294-313. doi: 10.3390/v6114294

202. Pune T, Kenny N, Eyles D, Moreira LA, O’Neill SL, Asgari S. Infection with the wMel and wMelPop strains of Wolbachia leads to higher levels of melanization in the hemolymph of Drosophila melanogaster, Drosophila simulans and Aedes aegypti. Dev Comp Immunol. (2011) 35:3605. doi: 10.1016/j.dci.2010.11.007

203. Gonzalez EA, Garg A, Tang J, Nazario-Toole AE, Wu LP. A Glutamate-dependent redox system in blood cells is integral for phagocytosis in Drosophila melanogaster. Curr Biol. (2013) 23:2319-24. doi: 10.1016/j.cub.2013.09.061

204. Teixeira L, Ferreira Á, Ashburner M. The bacterial symbiont Wolbachia induces resistance to RNA viral infections in Drosophila melanogaster. PLoS Biol. (2008) 6:e1000002. doi: 10.1371/journal.pbio.1000002

205. Gupta V, Vasanthakrishnan RB, Siva-Jothy J, Monteith KM, Brown SP, Vale PF. The route of infection determines Wolbachia antibacterial protection in Drosophila. Proc R Soc B Biol Sci. (2017) 284:20170809. doi: 10.1098/rspb.2017.0809

206. Salz HK, Erickson JW. Sex determination in Drosophila: the view from the top. Fly. (2010) 4:60-70. doi: 10.4161/fly.4.1.11277

207. Wu B, Ma L, Zhang E, Du J, Liu S, Price J, et al. Sexual dimorphism of sleep regulated by juvenile hormone signaling in Drosophila. PLoS Genet. (2018) 14:e1007318. doi: 10.1371/journal.pgen. 1007318

Conflict of Interest: The authors declare that the research was conducted in the absence of any commercial or financial relationships that could be construed as a potential conflict of interest.

Copyright (C) 2020 Belmonte, Corbally, Duneau and Regan. This is an open-access article distributed under the terms of the Creative Commons Attribution License (CC $B Y)$. The use, distribution or reproduction in other forums is permitted, provided the original author(s) and the copyright owner(s) are credited and that the original publication in this journal is cited, in accordance with accepted academic practice. No use, distribution or reproduction is permitted which does not comply with these terms. 